\title{
Structural and Functional Comparison of SARS-CoV-2-Spike Receptor Binding Domain Produced in Pichia pastoris and Mammalian Cells
}

Argentinian AntiCovid Consortium*: Claudia R. Arbeitman, ${ }^{1,2,3}$ Gabriela Auge, ${ }^{1,4}$ Matías Blaustein, ${ }^{1,4}$ Luis Bredeston, ${ }^{5,6}$ Enrique S. Corapi, ${ }^{4}$ Patricio O. Craig, ${ }^{7,8}$ Leandro A. Cossio, ${ }^{9,22}$ Liliana Dain, ${ }^{1,4,10}$ Cecilia D'Alessio, ${ }^{1,4}$ Fernanda Elias, ${ }^{11}$ Natalia B. Fernández, ${ }^{1,4}$ Javier Gasulla, ${ }^{1,4,12}$ Natalia Gorojovsky, ${ }^{7,8}$ Gustavo E. Gudesblat, ${ }^{1,4}$ María G. Herrera, ${ }^{1,4}$ Lorena I. Ibañez, ${ }^{13,14}$ Tommy Idrovo, ${ }^{4}$ Matías Iglesias Randon, ${ }^{5,8}$ Laura Kamenetzky, ${ }^{4,15}$ Alejandro D. Nadra, ${ }^{1,4}$ Diego G. Noseda ${ }^{16}$, Carlos H. Paván, ${ }^{17,18}$ María F. Pavan, ${ }^{13,14}$ María F. Pignataro, ${ }^{4}$ Ernesto Roman, ${ }^{6,7}$ Lucas A. M. Ruberto, ${ }^{19,20,21}$ Natalia Rubinstein, ${ }^{1,4}$ Javier Santos, ${ }^{1,4,7}$ Francisco Velazquez Duarte ${ }^{4,8}$ and Alicia M. Zelada ${ }^{9,22}$.

${ }^{1}$ Consejo Nacional de Investigaciones Científicas y Técnicas (CONICET). Godoy Cruz 2290 C1425FQB, Buenos Aires, Argentina.

${ }^{2}$ GIBIO-Universidad Tecnológica Nacional-Facultad Regional Buenos Aires. Medrano 951 C1179AAQ, Buenos Aires, Argentina.

${ }^{3}$ Theoretical Physics and Center of Interdisciplinary Nanostructure Science and Technology, Universität Kassel. Heinrich-Plett-Str. 40, 34132, Kassel, Germany.

${ }^{4}$ Universidad de Buenos Aires. Facultad de Ciencias Exactas y Naturales. Departamento de Fisiología y Biología Molecular y Celular. Instituto de Biociencias, Biotecnología y Biología Traslacional (iB3). Buenos Aires, Argentina.

${ }^{5}$ Universidad de Buenos Aires. Facultad de Farmacia y Bioquímica. Departamento de Química Biológica. Junín 965 C1113AAD. Buenos Aires, Argentina.

${ }^{6}$ CONICET-Universidad de Buenos Aires. Instituto de Química y Fisicoquímica Biológicas. (IQUIFIB). Buenos Aires, Argentina.

${ }^{7}$ Universidad de Buenos Aires. Facultad de Ciencias Exactas y Naturales. Departamento de Química Biológica. Buenos Aires, Argentina.

${ }^{8}$ CONICET-Universidad de Buenos Aires. Instituto de Química Biológica de la Facultad de Ciencias Exactas y Naturales (IQUIBICEN). Buenos Aires, Argentina.

${ }^{9}$ Universidad de Buenos Aires. Facultad de Ciencias Exactas y Naturales. Departamento de Fisiología y Biología Molecular y Celular. Laboratorio de Agrobiotecnología. Buenos Aires, Argentina.

${ }^{10}$ Centro Nacional de Genética Médica, Avda Las Heras 2670, 3er piso, C1425ASP, Buenos Aires, Argentina. 
${ }^{11}$ Instituto de Ciencia y Tecnología Dr. César Milstein (Consejo Nacional de Investigaciones Científicas y Técnicas-Fundación Pablo Cassará). Saladillo 2468 C1440FFX, Buenos Aires, Argentina.

${ }^{12}$ Universidad Nacional de la Plata-CONICET. Centro de Investigaciones del Medio Ambiente (CIM). La Plata, Argentina.

${ }^{13}$ Consejo Nacional de Investigaciones Científicas y Técnicas (CONICET). Instituto de Ciencia y Tecnología Dr. César Milstein. Saladillo 2468, C1440FFX, Buenos Aires, Argentina.

${ }^{14}$ CONICET-Universidad de Buenos Aires. Instituto de Química Física de los Materiales, Medio Ambiente y Energía (INQUIMAE), Buenos Aires, Argentina.

${ }^{15}$ CONICET-Universidad de Buenos Aires. Facultad de Medicina. Instituto de Investigaciones en Microbiología y Parasitología (IMPaM). Buenos Aires, Argentina.

${ }^{16}$ Universidad Nacional de San Martín-CONICET. Instituto de Investigaciones Biotecnológicas (IIBio). San Martín, Buenos Aires, Argentina.

${ }^{17}$ Universidad de Buenos Aires. Facultad de Farmacia y Bioquímica. Buenos Aires, Argentina.

${ }^{18}$ CONICET-Universidad de Buenos Aires. Facultad de Medicina. LANAIS-PROEM. Instituto de Química y Fisicoquímica Biológicas. (IQUIFIB). Buenos Aires, Argentina.

${ }^{19}$ Universidad de Buenos Aires. Facultad de Farmacia y Bioquímica. Departamento de Microbiología, Inmunología, Biotecnología y Genética. Buenos Aires, Argentina.

${ }^{20}$ CONICET-Universidad de Buenos Aires. Facultad de Farmacia y Bioquímica. Instituto de Nanobiotecnología (NANOBIOTEC). Buenos Aires. Argentina.

${ }^{21}$ Instituto Antártico Argentino. Ministerio de Relaciones Exteriores y Culto. Buenos Aires, Argentina.

${ }^{22}$ CONICET-Universidad de Buenos Aires. Instituto de Biodiversidad y Biología Experimental y Aplicada (IBBEA). Buenos Aires, Argentina.

*All authors (listed in alphabetical order) contributed equally to this work.

Contact E-mail: anticovid.arg@gmail.com

\section{Abbreviations:}

ACE2, angiotensin-converting enzyme 2; ASA, accessible surface area; $C D$, circular dichroism; CoV, Coronavirus; EDTA, ethylenediaminetetraacetic acid; EndoH, Endo- $\beta$ - $\mathrm{N}$-acetylglucosaminidase $\mathrm{H}$; ER, endoplasmic reticulum; ESI-MS, electrospray ionization mass spectrometry; GST, glutathione S-transferase; HPLC, high-performance liquid chromatography; IPTG, isopropyl $\beta$-D-1-thiogalactopyranoside; MALDI-TOF, 
matrix-assisted laser desorption/ionization-time-of-flight mass spectrometry; $\mathrm{NTA}-\mathrm{Ni}^{2+}$, nickel-charged nitrilotriacetic acid affinity resin; PCR, polymerase chain reaction; PDB, Protein Data Bank; PNGaseF, Peptide-N4-(N-acetyl-beta-glucosaminyl) asparagine amidase; RBD, receptor binding domain; RBM, receptor-binding motif; SARS-CoV-1, severe acute respiratory syndrome coronavirus 1 ; SARS-CoV-2, severe acute respiratory syndrome coronavirus 2; SDS-PAGE, polyacrylamide gel electrophoresis; SEC, size exclusion chromatography; TFA, trifluoroacetic acid; SDS-PAGE, SDS polyacrylamide gel electrophoresis. 


\section{Abstract}

The yeast Pichia pastoris is a cost-effective and easily scalable system for recombinant protein production. In this work we compared the conformation of the receptor binding domain (RBD) from SARS-CoV-2 Spike protein expressed in P. pastoris and in the well established HEK-293T mammalian cell system. RBD obtained from both yeast and mammalian cells was properly folded, as indicated by UV-absorption, circular dichroism and tryptophan fluorescence. They also had similar stability, as indicated by temperature-induced unfolding (observed $T_{\mathrm{m}}$ were $50^{\circ} \mathrm{C}$ and $52^{\circ} \mathrm{C}$ for RBD produced in P. pastoris and HEK-293T cells, respectively). Moreover, the stability of both variants was similarly reduced when the ionic strength was increased, in agreement with a computational analysis predicting that a set of ionic interactions may stabilize RBD structure. Further characterization by HPLC, size-exclusion chromatography and mass spectrometry revealed a higher heterogeneity of RBD expressed in P. pastoris relative to that produced in HEK-293T cells, which disappeared after enzymatic removal of glycans. The production of RBD in P. pastoris was scaled-up in a bioreactor, with yields above $45 \mathrm{mg} / \mathrm{L}$ of $90 \%$ pure protein, thus potentially allowing large scale immunizations to produce neutralizing antibodies, as well as the large scale production of serological tests for SARS-CoV-2.

\section{Introduction}

The COVID-19 outbreak was first recognized in December 2019 in Wuhan, China ${ }^{1}$. Since then, this virus has spread to all parts of the world, resulting in a total of 29415168 infected individuals and 931934 deaths by September $14^{\text {th }}, 2020$ 
(https://www.coronatracker.com). The causative agent is a coronavirus that causes a severe acute respiratory syndrome (SARS). This SARS-related coronavirus (SARSr-CoV) has been designated as SARS-CoV-2.

Coronaviruses are enveloped non-segmented positive sense RNA viruses ${ }^{2}$ that have four open reading frames (ORFs) for structural proteins -Spike, Envelope, Membrane, and Nucleocapsid- ${ }^{3,4}$, from which Spike is the primary determinant of CoVs tropism. Spike mediates the viral and cellular membrane fusion by binding mainly to the angiotensin-converting enzyme 2 (ACE2), a homologue of $A C E^{5,6}$.

The SARS-CoV-2 genome has 29903 nucleotides in length ${ }^{7}$, sharing $79 \%$ and $50 \%$ sequence identity with SARS-CoV-1 and MERS-CoV genomes, respectively ${ }^{8}$. Genetic studies suggest that both viruses originated from bat $\mathrm{CoVs}^{8,9}$, with civet cats as intermediate hosts in the case of SARS-CoV- $1^{10}$, and pangolins in the case of SARS-CoV- $2^{11,12}$. Among the structural proteins, the Envelope protein has the highest sequence similarity between SARS-CoV-2 and SARS-CoV-1 (96\% identity), while the Spike protein, responsible for the interaction with the host receptor, the largest sequence divergence $(76 \% \text { identity with SARS-CoV-1 })^{13}$. It has been suggested that the divergence of Spike could be related to an increased immune pressure ${ }^{1}$. Consistently with the proposed role of pangolins as SARS-CoV-2 intermediate hosts, CoVs from pangolins share the highest genetic similarity with this virus in the region encoding the receptor binding domain (RBD) of the Spike protein ${ }^{11,14}$.

Due to its important role for SARS-CoV-2 entry into the host cell, Spike is the most studied protein of this virus. This transmembrane glycosylated protein is composed of 1273 amino acid assemblies as a homotrimer that forms spikes that protrude from the virus envelope. Spike has two domains, named S1 and S2. Residues 
319-591 from S1 correspond to the RBD, responsible for the interaction with ACE $2^{15}$. RBD binds with high affinity to the ACE2, located on the outer surface of the cell membrane, which acts as a SARS-CoV-2 receptor since it mediates the fusion of the virus to the cell membrane ${ }^{16}$. Spike also includes a transmembrane domain and a fusion peptide ${ }^{17}$.

Molecular dynamics simulations suggest that internal motions of the Spike trimer are important to expose the RBD domain so it can interact with the target receptor. However, part of the time RBD domain is hidden within the rest of the Spike protein, and this process is mediated by protein motions of high amplitude. The structure of RBD-ACE2 protein complex and the structure of Spike (as the full-length and trimeric form of the protein) were determined by X-ray crystallography and cryo-EM ${ }^{16,18-20}$.

RBD is a protein domain of 220 residues, it has nine cysteine residues (eight of them forming disulfide bonds) (Figure 1) and two $N$-glycosylation sites (N331 and N343). The addition of glycan moieties might have a relevant role on the in vivo protein folding process, on the dynamics, stability and solvent accessibility of RBD and also on its immunogenicity ${ }^{21,22}$. RBD is not a globular protein domain; it has a central twisted antiparallel beta-sheet formed by five strands decorated with secondary structure elements (short helices and strands) and loops ${ }^{19}$. The secondary structure analysis of the protein shows $12.4 \%$ helix, $33.0 \%$ sheet, $19.1 \%$ turn, and $35.6 \%$ coil. 


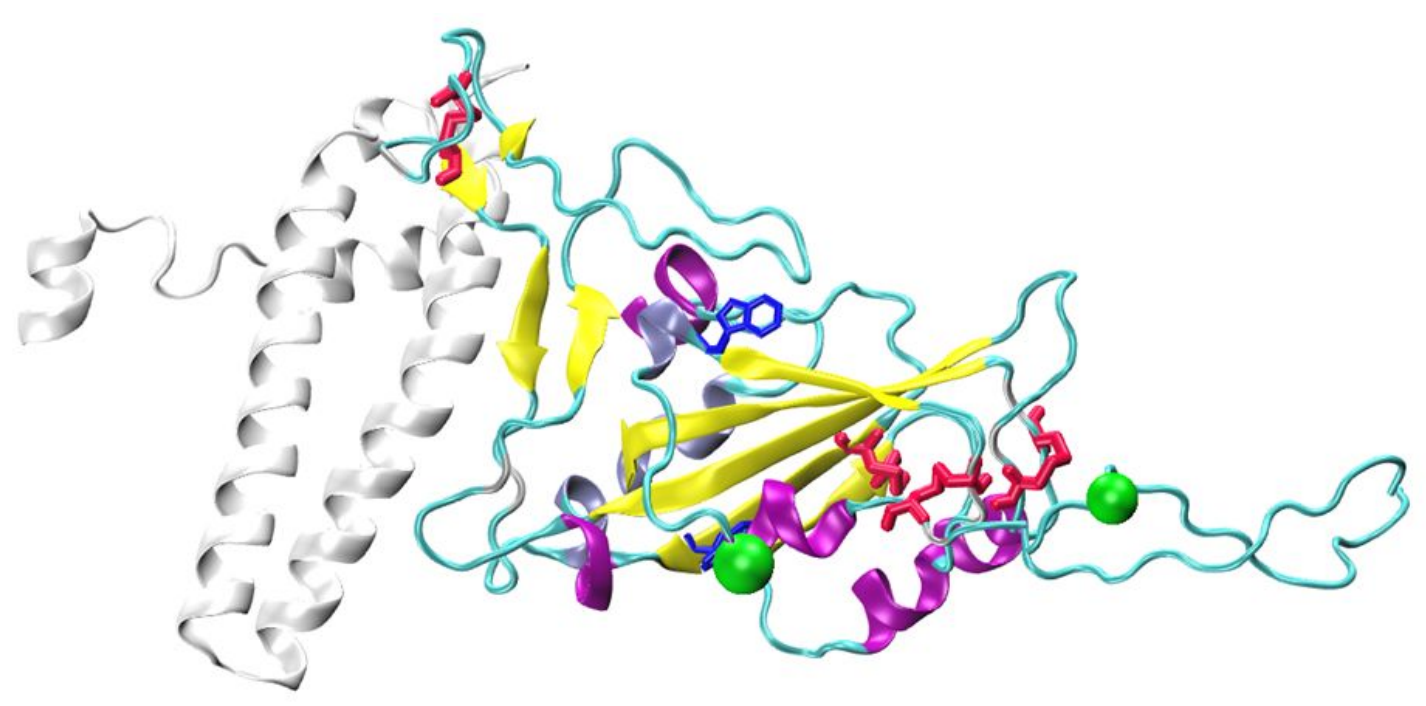

Figure 1. Structure of Sars-Cov-2 Receptor Binding Domain bound to ACE2. The secondary structure elements of RBD are differentially colored (Alpha helices: purple, 3_10 helices: iceblue, beta strands: yellow, and turns/coil: cyan). Disulfide bridges (red) and tryptophan residues (blue) are shown as sticks, while $\mathrm{N}$-glycosylation asparagine residues (green) are shown as VDW spheres. The region of ACE2 encompassing residues 1-115 (colored white) which interacts with RBD is also shown. The structure was generated using PDB structures $6 \mathrm{xm} 0$ and $6 \mathrm{m0j}$.

Despite its medium size of $25 \mathrm{kDa}, \mathrm{RBD}$ is an example of a challenging protein domain to express in heterologous systems due to its complex topology (Figure 1). Nevertheless, it is of high importance to produce and purify RBD at low-cost and efficiently, since this domain is extensively used for the development of serological test kits as well as an immunogen, both for the production of animal immune sera and for vaccine development ${ }^{23}$. While $E$. coli is a cost-efficient system for the expression of many proteins, it is unlikely to be the case for RBD due to its requirement of disulfide bond formation and glycosylation for its proper expression and folding. For this reason, RBD is usually expressed in mammalian as well as insect cells ${ }^{24,18}$.

The methylotrophic yeast Pichia pastoris is an alternative cost-effective eukaryotic system that allows relatively easy scaling-up of recombinant protein production, and which has previously been used for the expression of SARS-CoV-1 RBD 
to produce a vaccine ${ }^{25}$. This yeast can use methanol as an exclusive carbon source. This molecule is also an inductor of the strong and tightly regulated AOX1 promoter ${ }^{26}$, which can therefore be used to drive recombinant protein expression. When cultured in bioreactors, P. pastoris can reach high cell densities, and more importantly, this organism allows the efficient secretion of recombinant proteins to the culture medium, which contains relatively low levels of endogenous proteins, thus allowing the straightforward purification of recombinant secretory proteins ${ }^{26}$.

In this work we expressed and purified SARS-CoV-2 Spike RBD from two different systems -the yeast $P$. pastoris and mammalian cells- and compared their structure, stability, glycosylation status, and immunogenicity in mice. Our work provides useful insights on the production of a key protein used in diagnosis and therapeutics to fight COVID-19 pandemia.

\section{Results}

\section{SARS-CoV-2 RBD Protein Sequence analysis}

Prior to designing the constructs to express Spike RBD domain from SARS-CoV-2 we looked for possible variation in its coding sequence in genomes publicly available at the Global Initiative for Sharing All Influenza Data (GISAID) database (https://www.gisaid.org) ${ }^{27}$. From a total of 75355 SARS-CoV-2 genome sequences available at GISAID, $85.8 \%$ (64,707 genomes) have $100 \%$ coverage of RBD (non truncated Spike proteins) with $100 \%$ of amino acid identity to the first published RBD sequence (Uniprot: QHN73795.1) ${ }^{28}$. This data set includes 38 Argentinean SARS-CoV-2 genomes. RBD sequences from the remaining genomes (14.2\%) were distributed as follows: $3.5 \%$ (6199/64707) have more than $99 \%$ of amino acid sequence identity (up to 2 amino acid 
substitutions or InDels), 1.4\% (925/64707) have more than $80 \%$ (up to 44 amino acid substitutions or InDels) and only 300 genomes have a lower amino acid identity relative to the first published sequence. Thus, we considered appropriate to express the predominant RBD form, spanning from residue 319 to 537 of Spike protein, which consists of a relatively compact domain, and includes a slightly disordered C-terminal stretch useful for protein engineering (Figure 1).

\section{Expression of RBD in mammalian and yeast cells}

The expression of RBD in mammalian cells (HEK-293T cell line) and in P. pastoris yielded significant quantities of protein $\left(\sim 5\right.$ and $10-13 \mathrm{mg} \mathrm{L}^{-1}$ of cell culture, respectively, at a laboratory scale). In both cases, the recombinant protein was fused to appropriate secretion signal peptides, IL2 export signal peptide for HEK-293T expression and Saccharomyces cerevisiae $\alpha$-factor secretion signal for P. pastoris expression. Both secretion signals allowed the recovery of mature RBD from cell culture supernatants.

Since RBD expressed in both eukaryotic systems included a C- terminal His tag, similar purification protocols were used in both cases. However, given that the physico-chemical conditions required for optimal growth of mammalian and yeast cells were completely different (HEK-293T cells were grown at $37{ }^{\circ} \mathrm{C}$ in a medium buffered to $\mathrm{pH} 7.4$, while $P$. pastoris were grown at $28^{\circ} \mathrm{C}$, buffered to $\mathrm{pH} 6.0$ ), the covalent structure, intactness, conformation, post translational modifications and stability of RBD might still differ depending on the expression system used. Additionally, both strategies involved the accumulation of soluble RBD in the supernatant, which can pose an extra challenge for unstable proteins. For these reasons, it was crucial to evaluate 
parameters such as protein aggregation, oxidation, and possible alterations in disulfide bond patterns of proteins obtained from the different media.

NTA-Ni ${ }^{2+}$-purified RBD from both HEK-293T and yeast exhibited high purity (>90\%), as judged by SDS-PAGE analysis (Figure 2A). RBD from HEK-293T cells migrated as a $35 \mathrm{KDa}$ single-smear band in SDS-PAGE $12 \%$, while RBD produced in P. pastoris migrated as one highly diffuse and more abundant band of $\sim 45-40 \mathrm{kDa}$, and a less abundant band of $\sim 35 \mathrm{kDa}$, the latter similar to that of RBD produced in HEK-293T cells.

HPLC profile analysis revealed that RBD produced in HEK-293T cells is highly homogeneous, as shown by its elution as a sharp peak at $48-49 \%$ of acetonitrile in a reverse phase C18 column, while RBD produced in $P$. pastoris showed a considerably broader peak, although it eluted at very similar acetonitrile concentration. In addition, two very small peaks appeared in the chromatogram of RBD produced in P. pastoris. The area corresponding to the full-length protein was approximately $87 \%$.

The SDS-PAGE analysis of RBD purified from yeast and mammalian cell culture supernatants suggested the existence of glycosylation as the main post-traslational modification in RBD, as its theoretical mass (deduced from the amino acid sequence) is $\sim 26 \mathrm{kDa}$ (Figure 2), while both recombinant RBD forms migrated as products of more than 32-35 kDa. This was expected, since two $\mathrm{N}$-glycosylation consensus sequences (NIT and NAT) are present at RBD N-terminal region. RBD from SARS-CoV-1 also bears three glycosylation sites at its $\mathrm{N}$-terminal region, and was found to be glycosylated ${ }^{25}$. 


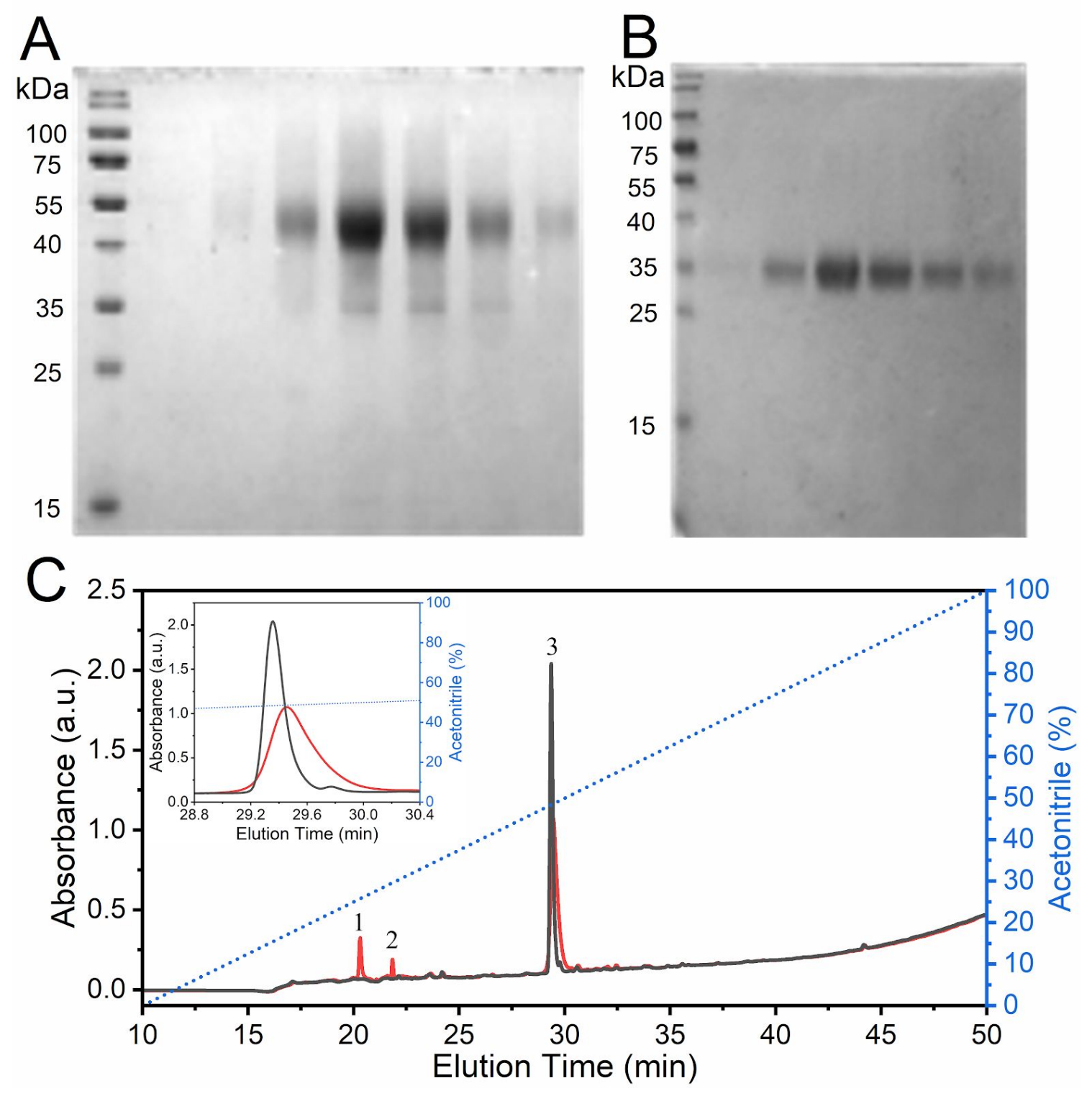

Figure 2. Analysis by SDS-PAGE and RP-HPLC of RBD produced in P. pastoris or HEK-293T, and purified by NTA-Ni ${ }^{2+}$. Analysis of recombinant RBD fractions eluted from a NTA-Ni ${ }^{2+}$ column by $300 \mathrm{mM}$ imidazole after purification from supernatants of a P. pastoris culture (A) or of HEK-293T cells (B). (C) Reverse Phase HPLC Analysis of RBD. Profiles for RBD produced in $P$. pastoris (red) and HEK-293T mammalian cells (black). The inset shows the expanded region of the chromatogram where the highest peaks eluted. The dashed blue line indicates the variation of acetonitrile (\% v/v) during the experiments. Peaks 1, 2 and 3 from RBD produced in $P$. pastoris correspond to areas of $10.1,2.8$ and $87.1 \%$, respectively.

Even though Coomassie Blue staining showed heterogeneity in protein size, incubation with PNGaseF, a peptide-endoglycanase that removes high mannose, complex and hybrid $\mathrm{N}$-glycans from proteins, homogenized all isoforms to a sharper 
band of $\sim 25-26 \mathrm{kDa}$, compatible with the predicted MW of deglycosylated RBD (26.5 kDa, Figure 3). The decrease in the molecular mass of RBD by endoglycanase digestion confirmed the existence of $\mathrm{N}$-glycosylations in both proteins. Moreover, glycans from P. pastoris-RBD - and not from HEK-293T-RBD - were also removed by EndoH, an endoglycanase that eliminates only high-mannose type glycans, which are the expected type in $P$. pastoris yeasts. These results strongly suggest that RBD from mammalian cells bears only complex or hybrid glycans, while RBD from $P$. pastoris only bears high mannose glycans. Moreover, the persistence of two bands in RBD from HEK-293T cells after exhaustive deglycosylation with PNGaseF suggests the existence of heterogeneous $\mathrm{O}$-glycosylation, although heterogeneity in amino acid sequence cannot be discarded either.

The identity of the RBD forms was corroborated by fragmentation, controlled proteolysis, peptide assignment and MS/MS sequencing (MALDI TOF TOF for tryptic peptides analysis). Figure 4 shows molecular masses and spectra from the intact mass analysis, which agree with values expected for the samples. 


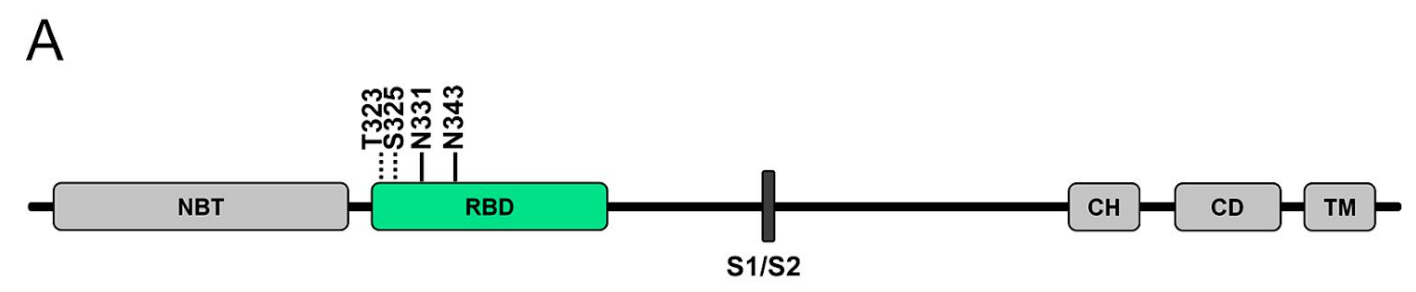

B

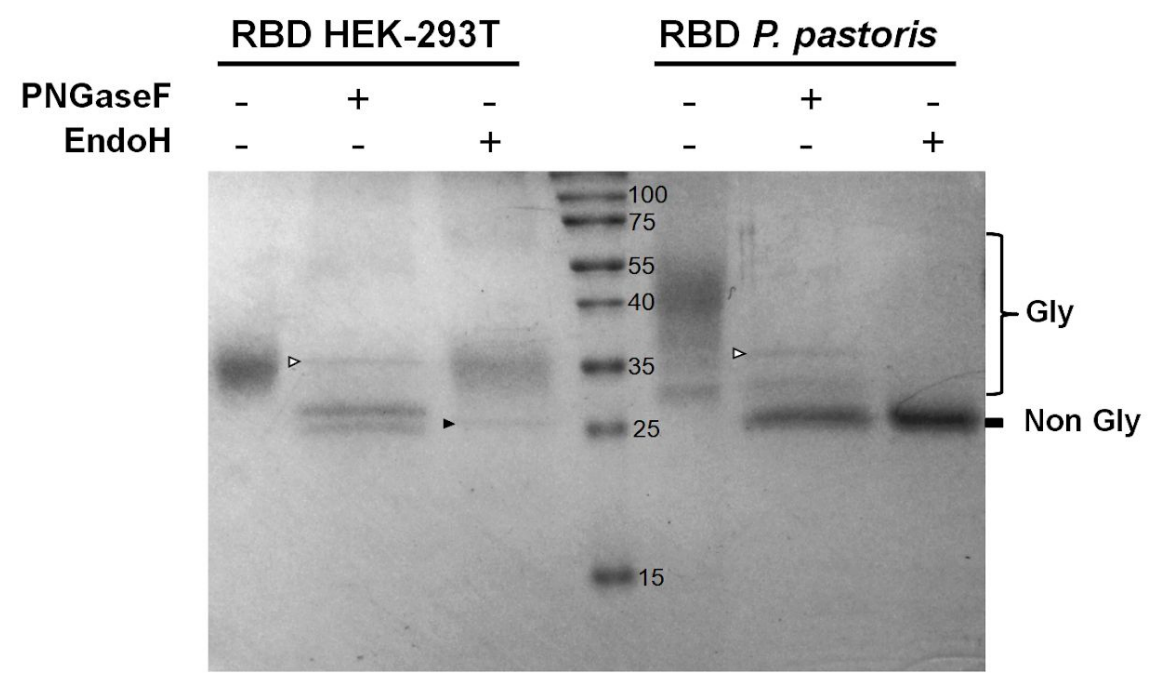

Figure 3. Analysis of the glycosylation status of RBD produced in HEK-293T and $P$. pastoris. (A) Schematic representation of SARS-CoV-2 S glycoprotein. N-terminal domain (NTD), receptor-binding domain (RBD), furin cleavage site (S1/S2), central helix $(\mathrm{CH})$, connector domain (CD), and transmembrane domain (TM) are displayed. Residues involved in RBD glycosylation are shown $(\mathrm{O}$ - and $\mathrm{N}$-glycosylations are indicated by dotted and solid lines, respectively). (B) Endoglycanase treatment of RBD. Purified RBD ( $3 \mathrm{ug}$ ) from mammalian or yeast culture supernatants was denatured 10 min at $100{ }^{\circ} \mathrm{C}$ and digested with PNGase $\mathrm{F}(500 \mathrm{mU})$ or EndoH $(5 \mathrm{mU})$ during $2 \mathrm{~h}$ at 37 ${ }^{\circ} \mathrm{C}$. Proteins were separated in a $14 \%$ SDS-PAGE gel. The positions of non-glycosylated and glycosylated RBD isoforms are indicated. The bands corresponding to PNGaseF (36 $\mathrm{KDa}$ ) and $\mathrm{EndoH}(29 \mathrm{KDa}$ ) are indicated by empty or full arrowheads, respectively. 


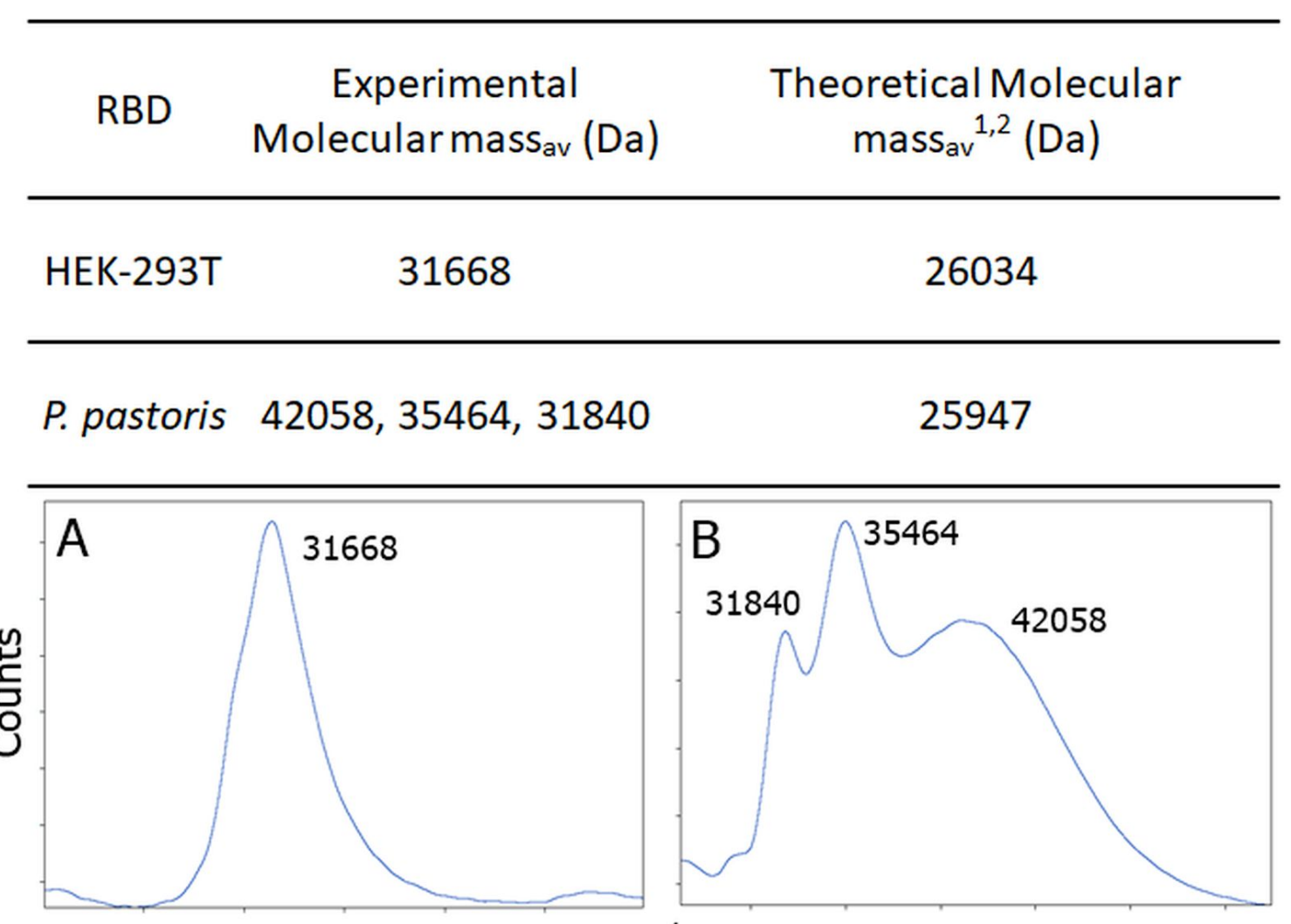

$\mathrm{m} / \mathrm{z}$

Figure 4. MALDI TOF Spectra for RBD Samples. (A) RBD prepared in HEK-293T and (B) RBD prepared in P. pastoris. As expected, the glycosylated species from $P$. pastoris have a broad mass.

The peptide spectrum matches - PSM - with significant score from the MS/MS analysis clearly showed that protein species present in the samples belonged to the RBD from SARS-CoV-2, (Table 2). The masses of peptides identified by MS/MS or peptide mass fingerprint (Table 2) were in good agreement with those expected from a proteotypic peptide prediction software -PeptideRank ${ }^{29}$, and from the information available from the Peptide Atlas database ${ }^{30}$ for peptides identified from SARS-CoV-2. To further validate the PSM findings, the data was also analyzed with COMET at Transproteomic Pipeline (a different MS/MS search engine), which produced similar results ${ }^{31,32}$.

As expected due to the dispersion in sizes, the FPNITNLCPFGEVFNATR peptide that harbors two glycosylation consensus sequences -NIT and NAT motifs- was not observed in the RBD samples from $P$. pastoris or HEK-293T cells. On the other hand, a deglycosylation of RBD produced in $P$. pastoris, followed by MS/MS analysis revealed a 
$\mathrm{m} / \mathrm{z}$ signal only present in that sample, in which two HexNAc moieties identified at the two $\mathrm{N}$ residues in FPNITNLCPFGEVFNATR (Figure S1).

Table 2. MS/MS Analysis Results for In-solution Digestion of RBD obtained from HEK-293T and from P. pastoris. Protein coverage was of $\sim 40$ and $\sim 60 \%$, for RBD produced in P. pastoris and HEK-293T cells, respectively. The experimentally obtained (MW (expt)) and the calculated (MW (calc)) molecular weights of the peptides, and their difference (ppM) are shown. The protein sequence of each construct is shown, red letters indicate the peptides identified either by MS/MS analysis or peptide mass fingerprint (less than 60 ppm error).

\begin{tabular}{|c|c|c|c|c|c|}
\hline Sample & $M W_{\text {(expt) }}(\mathrm{Da})$ & $M_{\text {(calc) }}(\mathrm{Da})$ & ppm & Peptide & Protein Sequence \\
\hline \multirow{6}{*}{ HEK-293T } & 989.48 & 989.52 & -47.17 & K.SNLKPFER.D & \multirow{6}{*}{$\begin{array}{l}\text { SRVQPTESIVRFPNITNLCPFG } \\
\text { EVFNATRFASVYAWNRKRISN } \\
\text { CVADYSVLYNSASFSTFKCYG } \\
\text { VSPTKLNDLCFTNVYADSFIR } \\
\text { GDEVRQIAPGQTGKIADYNYK } \\
\text { LPDDFTGCVIAWNSNNLDSKV } \\
\text { GGNYNYLYRLFRKSNLKPFER } \\
\text { DISTEIYQAGSTPCNGVEGFN } \\
\text { CYFPLQSYGFQPTNGVGYQP } \\
\text { YRVVVLSFELLHAPATVCGPK } \\
\text { KSTNLVKNKLETGHHHHHH }\end{array}$} \\
\hline & 1112.49 & 1112.54 & -42.78 & R.FASVYAWNR.K & \\
\hline & 1217.53 & 1217.58 & -41.21 & K.VGGNYNYLYR.L & \\
\hline & 2045.92 & 2045.99 & -31.94 & $\begin{array}{l}\text { K.LNDLCFTNVYADSFVIR.G } \\
\text { +Carbamidomethyl (C) }\end{array}$ & \\
\hline & 2264.98 & 2265.04 & -24.05 & $\begin{array}{l}\text { K.LPDDFTGCVIAWNSNNLDSK.V } \\
\text { +Carbamidomethyl (C) }\end{array}$ & \\
\hline & 2372.04 & 2372.10 & -23.92 & $\begin{array}{l}\text { R.ISNCVADYSVLYNSASFSTFK.C } \\
\text { +Carbamidomethyl (C) }\end{array}$ & \\
\hline \multirow{3}{*}{ P. pastoris } & 1027.51 & 1027.57 & -52.05 & R.VQPTESIVR.F & \multirow{3}{*}{$\begin{array}{l}\text { RVQPTESIVRFPNITNLCPFGE } \\
\text { VFNATRFASVYAWNRKRISNC } \\
\text { VADYSVLYNSASFSTFKCYGV } \\
\text { SPTKLNDLCFTNVYADSFVIRG } \\
\text { DEVRQIAPGQTGKIADYNYKL } \\
\text { PDDFTGCVIAWNSNNLDSKVG } \\
\text { GNYNYLYRLFRKSNLKFERDI } \\
\text { STEIYQAGSTPCNGVEGFNCY } \\
\text { FPLQSYGFQPTNGVGYQPYR } \\
\text { VVVLSFELLHAPATVCGPKKST } \\
\text { NLVKNKLPETGHHHHHH }\end{array}$} \\
\hline & 1217.52 & 1217.58 & -49.42 & K.VGGNYNYLYRLL & \\
\hline & 2045.89 & 2045.99 & -46.60 & $\begin{array}{l}\text { K.LNDLCFTNVYADSFVIR.G } \\
\text { +Carbamidomethyl (C) }\end{array}$ & \\
\hline
\end{tabular}

\section{Conformational characterization of RBD forms by UV absorption}

Different analytical techniques were used to characterize proteins produced in yeast or mammalian cells. The UV absorption spectra of both recombinant proteins were very similar; they are dominated by a high content of tyrosine residues (16 Tyr, 2 Trp, 15 Phe, 4 disulfide bonds), as indicated by bands at approximately 276.0 and 281.0 

perpetuity. It is made available under aCC-BY 4.0 International license.

$\mathrm{nm}$. The absence of light scattering -suggested by the absence of a typical slope between 340 and $300 \mathrm{~nm}$ - strongly indicated that the proteins do not form soluble aggregates (Figure 5). However, freezing and thawing resulted in protein precipitation when RBD concentration was higher than $80 \mu \mathrm{M}$ (data not shown).

The fourth derivative of absorption spectra can be used to evaluate RBD native conformation. Spectra corresponding to RBD produced in HEK-293T cells and $P$. pastoris were superimposable (Figures 6B and C), suggesting a similar packing of the aromatic residues. In particular, the positive band at $290.4 \mathrm{~nm}$ corresponding to Trp residues observed in the native state of RBD (Figure $6 \mathrm{C}$ ) showed a significant red shift compared to the $288 \mathrm{~nm}$ band of $\mathrm{N}$-acetyl-L-tryptophanamide (NATA), suggesting that Trp residues in RBD are not fully exposed to the solvent (Figure 6B). Also the negative band at $287.8 \mathrm{~nm}$ (a contribution of Tyr and Trp residues) showed a significant red shift compared to that observed for the fully exposed NATA and N-acetyl-L-tyrosinamide, NAYA. Similarly, a band corresponding to Tyr $(280.4 \mathrm{~nm})$ showed a shift to $279 \mathrm{~nm}$ (NAYA). 

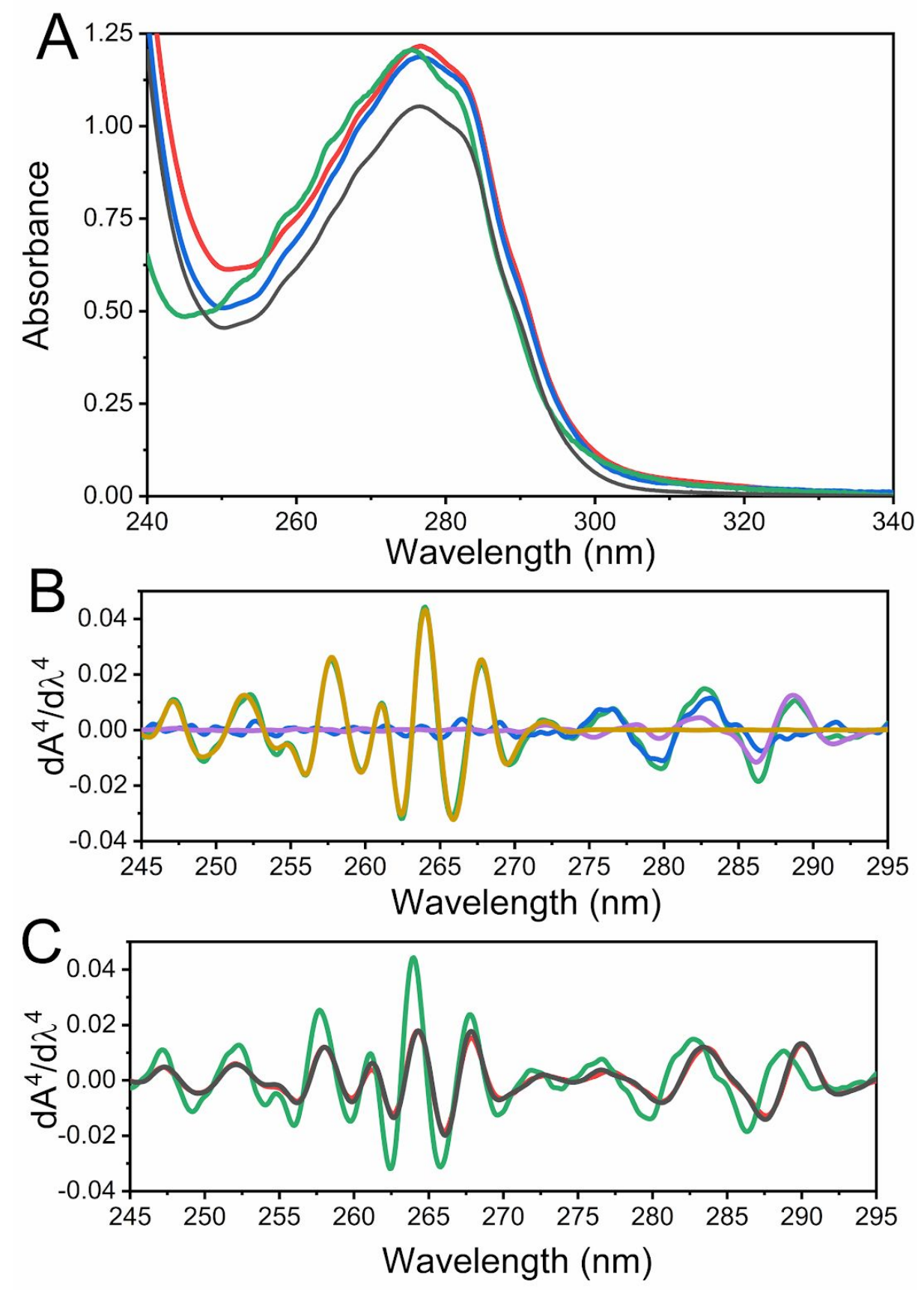

Figure 5. Absorption Spectroscopy. (A) Spectra corresponding to purified RBD produced in HEK-293T cells (black), P. pastoris (clones 1 (blue) and 7 (red), and a simulated RBD spectrum (green) $(27.5 \mu \mathrm{M})$ calculated from its composition of aromatic amino acid (15 Phe, 15 Tyr and 2 Trp in RBD). (B) Fourth derivative spectra corresponding to the aromatic amino acids (Tyr (blue), Trp (violet), Phe (yellow)) and a simulated RBD spectrum (green). (C) Comparison between the fourth derivative spectra from RBD obtained in HEK-293T (black), P. pastoris RBD Clone 7 (red) and the simulated spectrum presented in A (green). 


\section{Hydrodynamic behavior of RBD forms analyzed by SEC-HPLC}

SEC-HPLC experiments of RBD produced in P. pastoris confirmed the absence of aggregated forms and showed a peak compatible with two species between 45-25 kDa (Figure 6). Deconvolution of the chromatogram in two components by fitting to two gaussian curve suggested that $\sim 60 \%$ of the signal comes from a higher molecular weight component $(>40 \mathrm{kDa}$ ), whereas the rest of the signal $\sim 40 \%$ corresponds to a lower molecular weight component $(<30 \mathrm{kDa})$. It is worth mentioning that the exclusion profile corresponding to RBD produced in HEK-293T cells superimposes with the latter, suggesting a more homogeneous glycosylation of the protein.
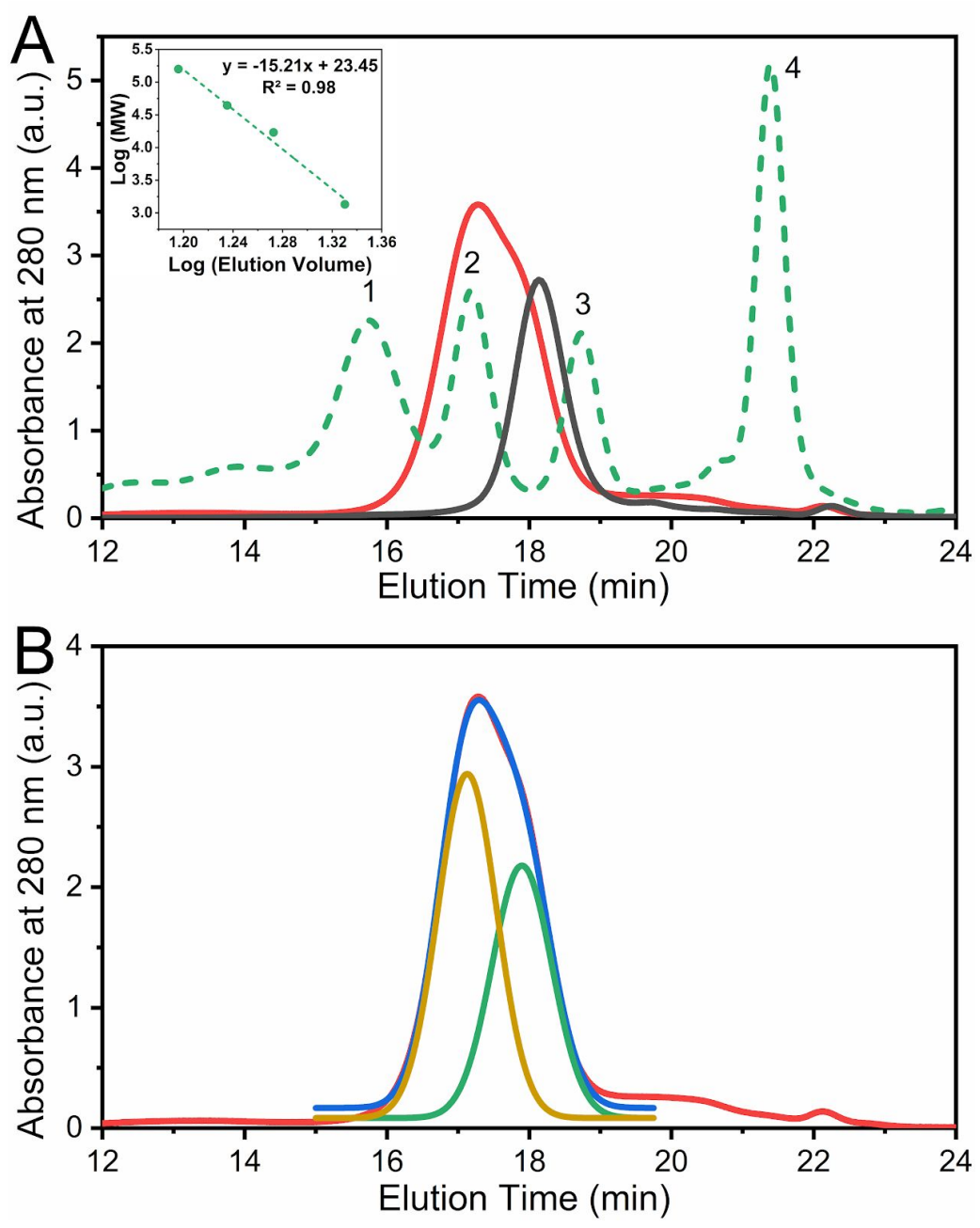

Figure 6. Hydrodynamic Behavior of RBD. (A) SEC-HPLC of RBD produced in P. pastoris (red), HEK-293T (black) and molecular weight markers (dashed green line). This 
analysis was carried out by injecting $50 \mu \mathrm{L}$ protein aliquots $(0.70$ and $0.75 \mathrm{mg} / \mathrm{mL}$ for RBD produced in $P$. pastoris and HEK-293T, respectively) in $20 \mathrm{mM}$ Tris- $\mathrm{HCl}, 100 \mathrm{mM}$ $\mathrm{NaCl}, \mathrm{pH} 7.0$ buffer. The inset shows the correlation between molecular weight and elution volume obtained from the molecular weight markers: (1) gammaglobulin (158 kDa), (2) ovoalbumin (44 kDa), (3) myoglobin (17 kDa), and (4) vitamin B12 (1350 Da). (B) Deconvolution analysis of the chromatographic profile from RBD from $P$. pastoris. The experimental profile (red), deconvolution of the peak in two different gaussian curves (green and yellow) and the sum of the deconvoluted peaks (blue) are compared.

\section{Conformational characterization of RBD forms analyzed by circular dichroism,}

\section{fluorescence and thermal-induced unfolding}

RBD produced in mammalian and $P$. pastoris cells showed superimposable far-UV circular dichroism (CD) spectra (Figure 7A), suggesting a similar secondary structure. Moreover, the CD spectra are identical to that observed for RBD from SARS-CoV-1 produced in yeast ${ }^{25}$. However, given the particular shapes of the $P$. pastoris and HEK-293T SARS-CoV-2 RBD far-UV CD spectra (which show a single minimum at $206 \mathrm{~nm}$ and a maximum at $230 \mathrm{~nm}$, the latter suggesting the contribution of aromatic residues to the spectra), it is difficult to estimate the secondary structure content by using standard sets of spectra.

We further studied the conformation of RBD produced in HEK-293T cells or $P$. pastoris by tryptophan fluorescence spectroscopy. Spectra corresponding to the native forms of RBD superimposed very well, suggesting that these aromatic residues are located in similar, apolar environments, as inferred by the maximal emission wavelengths observed (337 nm) (Figure 8B). The addition of $4.0 \mathrm{M} \mathrm{GdmCl}$ resulted in a red shift to 353-354 $\mathrm{nm}$, a result compatible with the exposure of the aromatic side chains to the solvent, and the total unfolding of the protein forms. Interestingly, unfolding of RBD produced in P. pastoris showed reversibility when $4.0 \mathrm{M} \mathrm{GdmCl}$ was diluted to 0.7 or $1.0 \mathrm{M}$, as judged by the blue shift from 353 to $337 \mathrm{~nm}$ and form 353 to 
bioRxiv preprint doi: https://doi.org/10.1101/2020.09.17.300335; this version posted September $17,2020$. The copyright holder for this preprint (which was not certified by peer review) is the author/funder, who has granted bioRxiv a license to display the preprint in perpetuity. It is made available under aCC-BY 4.0 International license.

$342 \mathrm{~nm}$, respectively. No reducing agents (e.g. DTT, 2-mercaptoethanol) were added to the protein sample, indicating that the dimension of the conformational space corresponding to the unfolded state of RBD was constrained by the native disulfide bonds. 

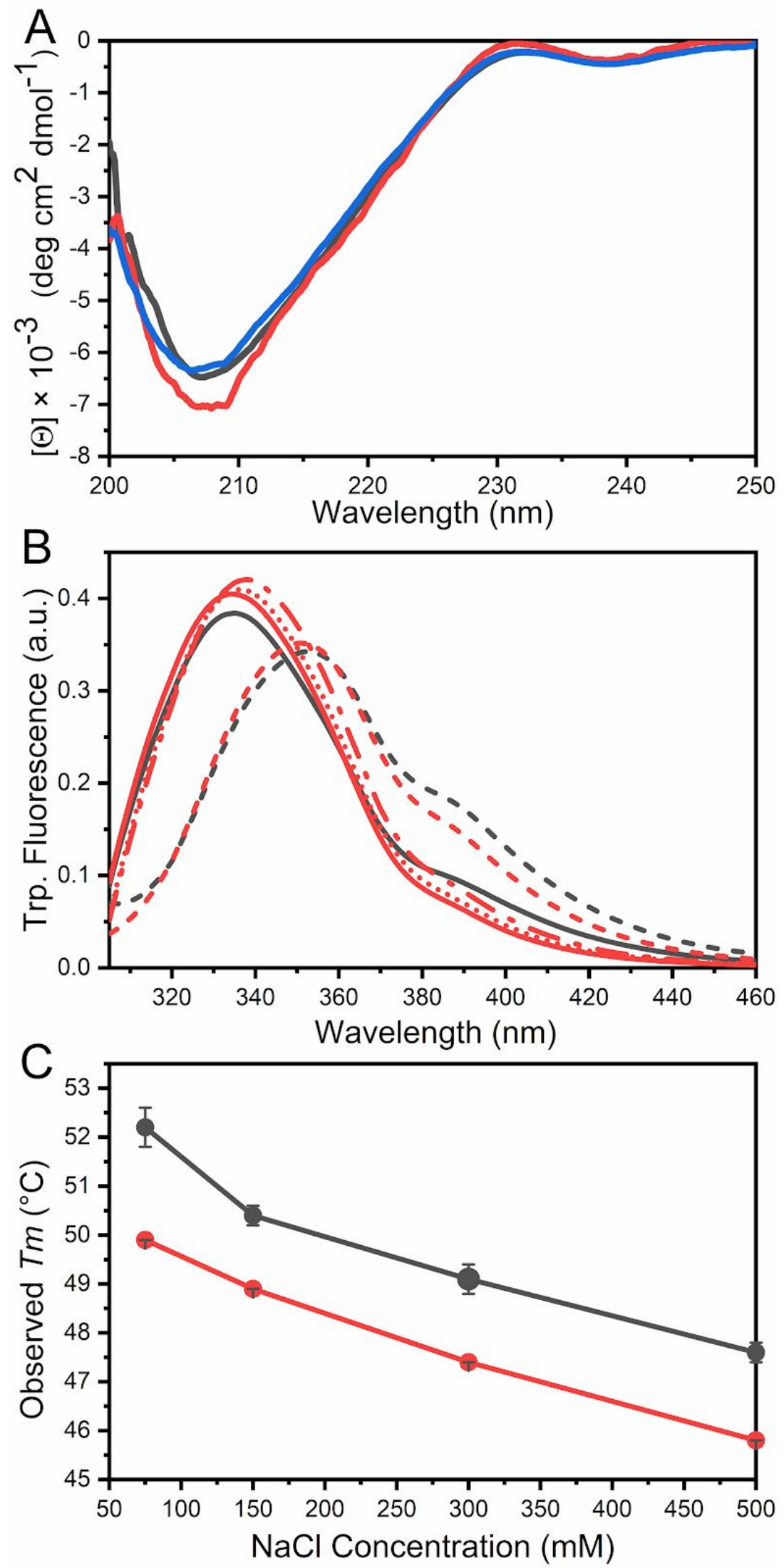
Figure 7. Conformation and stability of Different Purified RBD Forms characterized by Circular Dichroism Spectroscopy, Tryptophan Fluorescence and Temperature-induced Denaturation. (A) Far-UV CD spectra of RBD produced in HEK-293T cells (black), and two different preparations of RBD produced in $P$. pastoris (red and blue). (B) Tryptophan fluorescence emission was monitored by excitation at $295 \mathrm{~nm}$ in $20 \mathrm{mM}$ Tris- $\mathrm{HCl}, 100 \mathrm{mM} \mathrm{NaCl}, \mathrm{pH} 7.0$ at $25^{\circ} \mathrm{C}$. The spectra of RBD obtained in HEK-293T (black) and in $P$. pastoris (red) are shown, in native conditions (solid line) and in the presence of $4.0 \mathrm{M} \mathrm{GdmCl}$ (dashed line) after a $3 \mathrm{~h}$ incubation. Refolding of RBD produced in $P$. pastoris was performed by dilution to final concentrations of $0.7 \mathrm{M}$ (red dot line) and 1.0 M (red dash-dot line) $\mathrm{GdmCl}$. (C) Stability analysis of RBD. Temperature-induced denaturation of RBD produced in P. pastoris (red) and HEK-293T cells (black) under different ionic strength conditions $(75,150,300$ and $500 \mathrm{mM} \mathrm{NaCl}$ ) was followed by Sypro-orange fluorescence.

The conformational stability of different RBD forms was studied through temperature unfolding experiments. Unfolding was monitored by fluorescence of Sypro-orange, an extrinsic probe that preferentially binds to proteins when they are in unfolded conformations. In these experiments, the observed $T_{\mathrm{m}}$ usually correlates with $T_{\mathrm{m}}$ obtained from differential scanning calorimetry experiments ${ }^{33}$. RBD produced in $P$. pastoris consistently showed a slightly lower $T_{m}$ value relative to that of RBD from HEK-293T cells (in all assessed conditions), an observation compatible with a reduced resistance to temperature-induced denaturation, which likely reflects a marginally lower conformational stability of RBD produced in P. pastoris (Figure 7C). When the unfolding process was studied at different ionic strengths, a significant increase in $T_{\mathrm{m}}$ was observed when $\mathrm{NaCl}$ concentration was reduced from 500 to $75 \mathrm{mM}$ (Figure 7C), suggesting that the tertiary structure of RBD is stabilized by ionic pair interactions.

\section{Computational analysis of RBD structure}

The dependence of the observed $T_{\mathrm{m}}$ on the $\mathrm{NaCl}$ concentrations, led us to hypothesize that increasing the ionic strength destabilizes RBD conformation by shielding key charged residues. Although the RBD structure suggests some energetic 
frustration, given that there are several clusters of positively charged residues on RBD surface ((1) R136, R139 and K140; (2) K126, R28, R191; (3) R37, K38, R39 and R148; (4) $\mathrm{R} 85, \mathrm{R} 90$ and $\mathrm{K99})^{19}$, our results suggest that these repulsive interactions are most likely compensated even in the context of the isolated RBD domain (i.e. without the rest of Spike or the ACE2 receptor). This would explain why increasing ionic strength has a major destabilizing effect.

The RBD crystallographic structure analysis indicates that residues have a particular distribution according to their type. The core subdomain (residues 333-442 and 504-526 on the Spike protein) is enriched in non-polar residues, whereas the receptor-binding motif (RBM) subdomain (residues 443-503) is enriched in polar ones. On the other hand, the charged residues are preferentially located close to the interface between the Core and RBM subdomains and form an electrostatic network (Figure 8).
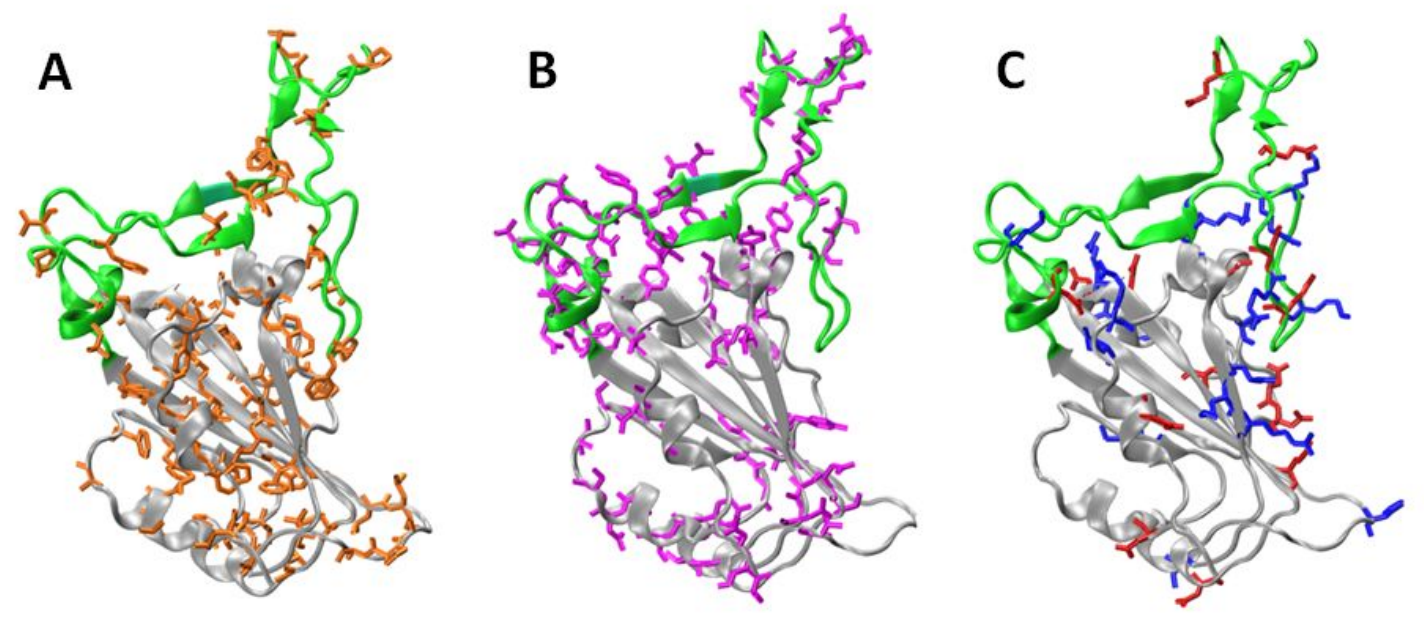

Figure 8. Subdomains and distribution of residue types on RBD. The Core (gray) and the RBM (green) regions are shown. Panels $A, B$, and $C$, shows the non-polar residues (orange: $A, C, G, I, L, M, F, P, W$ and $V$ ), polar (violet: N, Q, S, T and Y), and charged residues (blue: basic $K, R$ and $H$, red: acid $D$ and $E$ ), respectively. To build the models we used the chain $\mathrm{E}$ of pdb structure $6 \mathrm{~m} 0 \mathrm{j}$. 
Among the 14 positively and negatively charged residue pairs interacting at a distance lower than $6 \AA$, 8 are in the core subdomain, 5 in the RBM, and 1 pair is between the Core and RBM subdomains (Table 3). The existence of 6 ionic pair interactions involving at least one occluded charged residue (D398, E406, D442, R454, D467, and R509) is also remarkable.

Table 3. Electrostatic pair interactions between negatively and positively charged residues.

\begin{tabular}{|c|c|c|c|c|c|}
\hline \multicolumn{6}{|c|}{$\begin{array}{c}\text { Ionic pair interactions - Distance in } \AA \\
\text { (ASA ratio \%) }\end{array}$} \\
\hline $\begin{array}{l}\text { E340-K356 } \\
(56 \% 40 \%)\end{array}$ & 3.6 & $\begin{array}{l}\text { E406*-R403 } \\
(13 \% 26 \%)\end{array}$ & 4.9 & $\frac{\text { D467*-R454* }}{(17 \% 2 \%)}$ & 3.4 \\
\hline $\begin{array}{c}\text { D398*-R355 } \\
\text { (0\% 29\%) }\end{array}$ & 2.8 & $\begin{array}{l}\text { D420-K424 } \\
\text { (22\% 21\%) }\end{array}$ & 3.0 & $\frac{\text { D467*-R457 }}{(17 \% 21 \%)}$ & 3.4 \\
\hline $\begin{array}{c}\text { D398*-R466 } \\
(0 \% 37 \%)\end{array}$ & 5.9 & $\begin{array}{c}\text { D442*-R509* } \\
(4 \% 2 \%)\end{array}$ & 3.1 & $\frac{\text { E471-K458 }}{(72 \% \text { 71\%) }}$ & 4.3 \\
\hline $\begin{array}{l}\text { D405-R403 } \\
(44 \% 26 \%)\end{array}$ & 3.1 & $\frac{\text { E465-R457 }}{(36 \% \text { 21\%) }}$ & 3.7 & $\begin{array}{l}\text { E516-R357 } \\
(28 \% 63 \%)\end{array}$ & 5.4 \\
\hline $\begin{array}{l}\text { D405-R408 } \\
\text { (44\% 76\%) }\end{array}$ & 4.8 & $\frac{\text { E465-K462 }}{(36 \% 88 \%)}$ & 5.5 & & \\
\hline
\end{tabular}

The $\mathrm{N}-\mathrm{O}$ distance between basic and acidic groups is shown at the right of each pair. The outlined residues correspond to the RBM region, and the other ones to the core. The values in brackets correspond to the accessibility of the interacting residues, expressed as the percentage of surface exposed. Occluded charged residues (ASA ratio $<20 \%)$ are marked with an asterisk. The index of each residue corresponds to the numbering in the Spike protein. For this analysis we used the structure of chain $E$ of the pdb code $6 \mathrm{m0j}^{19}$.

The importance of these interactions merits further analysis, as they may modulate the conformational dynamics of the RBM, the transitions of the RBD in the Spike trimmer, and/or the interaction with the ACE2 receptor. 


\section{Immune Response elicited by RBD produced in $P$. pastoris in mice}

With the aim of evaluating the ability of the RBD protein produced in P. pastoris to stimulate immune response we assessed antibody production in mice by an ELISA assay using plates coated with RBD produced either in HEK-293T or in P. pastoris. After

a first dose of antigen plus adjuvants, mice presented higher antibody titers than controls, and after a second dose, the levels of antibodies increased significantly in a short period of time (20 days) relative to the first dose (Figure 9A). No significant differences in antibody titers were observed between plates coated with RBD from $P$. pastoris or from HEK-293T cells. Thus, immunization of mice with RBD produced in $P$. pastoris plus adjuvant induces a high level of specific IgG class antibodies. Next, Western blots were performed in which RBD produced either in $P$. pastoris or in HEK-293T cells was detected with a serum from mice immunized with RBD produced in HEK-293T cells (kindly provided by Dr. Juan Ugalde, University of San Martín, Figure 9B, left), the previously used mouse polyclonal serum from mice immunized with RBD produced in $P$. pastoris (Figure 9B, middle), or a primary antibody against the His tag present in both RBD recombinant proteins (Figure 9B, right). Similar bands were observed in all three blots. 


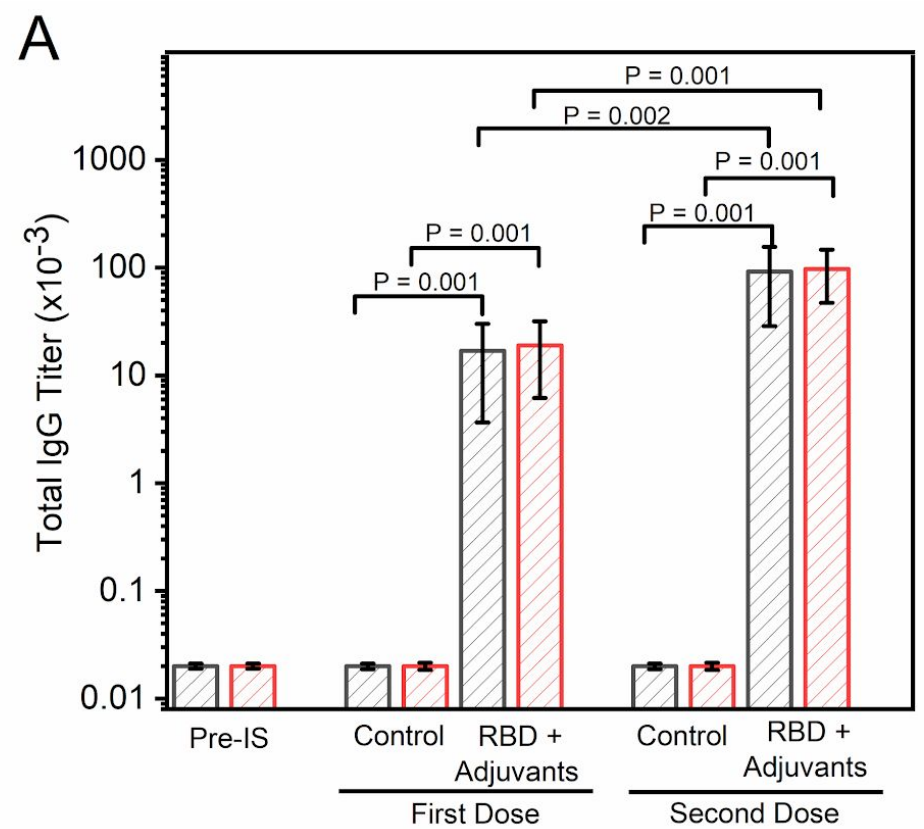

B

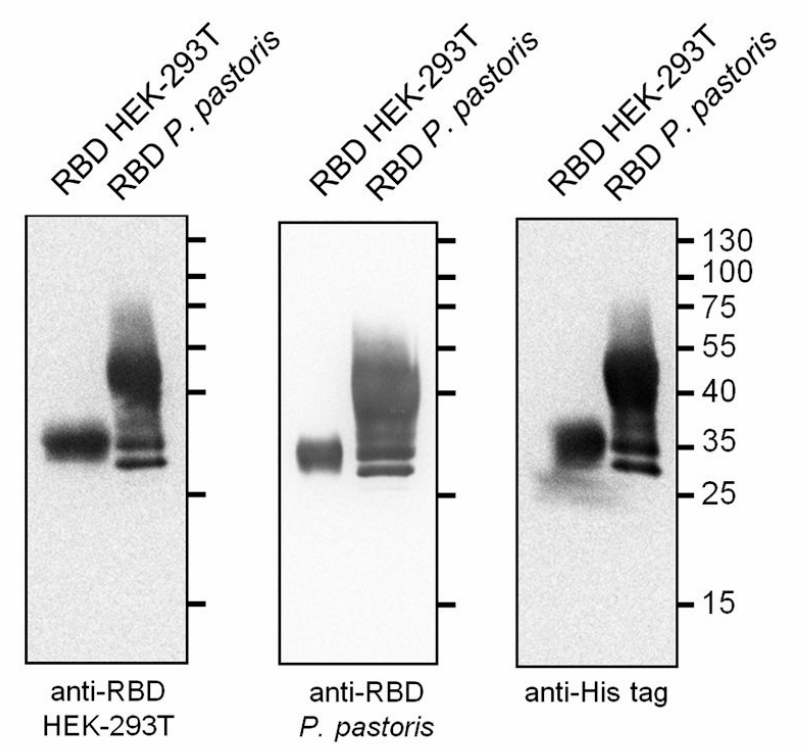

Figure 9. Evaluation of the cross-reactivity of antibodies produced in mice immunized with $P$. pastoris RBD. (A) Titers of antibodies obtained by immunization with RBD from $P$. pastoris plus adjuvants. Each bar represents the group mean $(n=5)$ for specific titers as determined by end-point-dilution ELISA. ELISA was performed with plates coated with RBD protein produced in HEK-293T cells (black sparse bars) or $P$. pastoris (red sparse bars). First dose corresponds to blood samples obtained 30 days post-first immunization, and second dose to samples obtained 20 days post-second immunization. Pre IS, Pre Immune Sera; RBD + Adjuvants, RBD produced in $P$. pastoris +

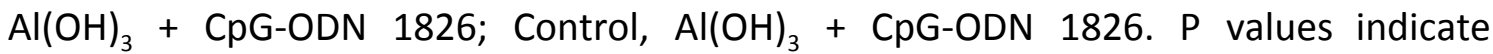
significant differences between different groups. Bars indicate SD. $P$ values (t-test) are shown for statistically significant differences $(p<0.05)$. (B) Purified RBD produced in HEK-293T $(1.0 \mu \mathrm{g})$ and in P. pastoris $(3.0 \mu \mathrm{g})$ were analyzed by Western blot using sera 
from mice immunized with RBD produced in HEK-293T (anti-RBD HEK-293T, left), or in $P$. pastoris (anti-RBD, P. pastoris center). As a control a primary antibody against the His tag present in both RBD recombinant proteins was used (right).

\section{Production of RBD by fermentation in bioreactor}

The fermentation of $P$. pastoris in a $7 \mathrm{~L}$ stirred-tank bioreactor for the production of recombinant RBD was carried out using a four-phase procedure described in Methods. In the batch phase, cell concentration reached a maximum level of $15.7 \mathrm{~g} \mathrm{DCW} / \mathrm{L}$ after $18 \mathrm{~h}$ of cultivation (Figure 10). At this stage, P. pastoris exhibited a maximum specific growth rate $\left(\mu_{\max }\right)$ of $0.21 \mathrm{~h}^{-1}$ and a biomass yield coefficient $\left(Y_{\mathrm{x} / \mathrm{s}}\right)$ of $0.39 \mathrm{~g} \mathrm{DCW} / \mathrm{g}$ of glycerol. After a spike of dissolved oxygen, the glycerol fed-batch phase was initiated by regulating the feeding in response to the level of dissolved oxygen (DO \%). Glycerol feeding was maintained for $22 \mathrm{~h}$, when biomass concentration reached a value of 60.4 g DCW/L. After glycerol feeding was stopped, the transition stage was performed by feeding with a glycerol (600 g/L):methanol (3:1) mixture for $5 \mathrm{~h}$, to allow a slow cell adaptation for the efficient utilization of methanol. At the end of this stage the biomass level reached $63.2 \mathrm{~g} \mathrm{DCW} / \mathrm{L}$. Next, the methanol fed-batch phase was initiated to induce recombinant $\mathrm{RBD}$ expression, through regulation of pure methanol feeding according to DO \%. After $48 \mathrm{~h}$ of methanol induction and a total fermentation time of $93 \mathrm{~h}$, the culture reached a biomass concentration of $75.3 \mathrm{~g} \mathrm{DCW} / \mathrm{L}$, which produced a final RBD yield of $45.0 \mathrm{mg} / \mathrm{L}$ (>90\% pure). Beyond that time point there was no significant change in cell concentration and antigen expression level (data not shown). At the end of the fermentation, a final volume of 5.5 liters of culture was reached, so that the total amount of RBD obtained was $247.5 \mathrm{mg}$, the volumetric productivity was $0.48 \mathrm{mg} / \mathrm{Lh}$, and the total productivity $2.66 \mathrm{mg} / \mathrm{h}$. 


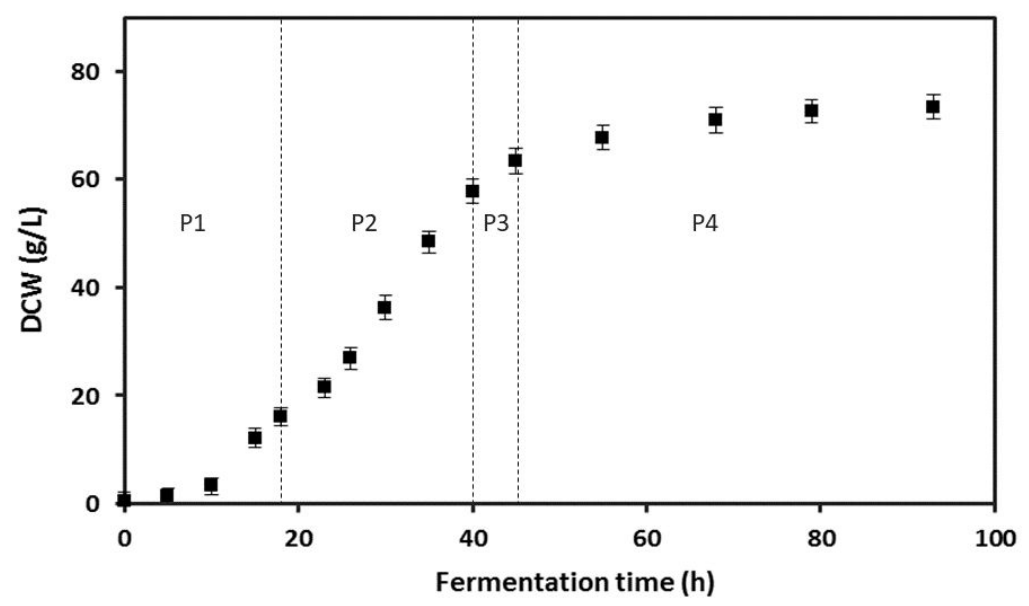

Figure 10. $P$. pastoris biomass concentration (g DCW/L) evolution during bioreactor fermentation. P1: batch phase in LSBM glycerol $40 \mathrm{~g} / \mathrm{L}, \mathrm{P} 2$ : Fed-batch phase with 600 $\mathrm{g} / \mathrm{L}$ glycerol solution, P3: Adaptation phase with glycerol (600 g/L):methanol (3:1) mixture, P4: Induction phase with methanol as the sole carbon source. Error bars indicate 2SD.

\section{Discussion}

This work materialized the first two goals of our consortium assembled to fight COVID-19 pandemia: (a) to express and characterize RBD from SARS-CoV-2, and (b) to produce RBD at low cost with high yield. We were able to express this protein in two different systems: P. pastoris and mammalian cells (HEK-293T), which allowed us to gain useful insights concerning RBD conformation and stability.

We attempted to express RBD in E. coli, even though an examination of its structure suggested that this system would not be suited for its expression due to the existence of 4 disulfide bonds and a non-globular shape. The $E$. coli SHuffle expression system only yielded insoluble RBD (in inclusion bodies) as expected, which was not further characterized as it was unsuitable for downstream applications (data not shown). In agreement with our results, in a previous attempt to express the similar RBD 
from SARS-CoV-1 Spike in E. coli, this protein was also found in the insoluble fraction, and neither its fusion to thioredoxin, nor to maltose-binding protein, increased its solubility. Moreover, while tagging the protein with glutathione S-transferase (GST) increased its solubility ${ }^{34}$, it remained strongly bound to the bacterial chaperone GroEL even after affinity purification ${ }^{35}$, thus making it unsuitable for downstream applications.

By contrast, RBD expression in HEK-293T and $P$. pastoris eukaryotic cells produced soluble and properly folded polypeptides. Their UV-absorption, CD and Trp-fluorescence spectra showed high similarity with those previously described for SARS-CoV-1 RBD produced in P. pastoris ${ }^{25}$. RBD expressed in both eukaryotic systems was also characterized by controlled proteolysis and mass spectrometry analysis. Remarkably, the peptide of sequence FPNITNLCPFGEVFNATR was not easily detected by mass spectrometry. A plausible and straightforward explanation for this result is that glycosylation of this peptide at positions N331 (NIT) and N343 (NAT) increases its mass, and thus takes the peptide out of the range of mass analysis. The sequence coverage corresponding to a similar N-terminal peptide of RBD produced in HEK-293T cells was also lower than expected as the peptide VQPTESIVR was not detected, which might be due to the presence of $O$-glycosylations in this stretch.

Proteins translocated to the ER are $\mathrm{N}$-glycosylated cotranslationally, and exactly the same glycan $\mathrm{Glc}_{3} \mathrm{Man}_{9} \mathrm{GlcNAc}_{2}$ is transferred to the $\mathrm{N}$ residue in the consensus sequence NXS/T (where $X$ cannot be $P$ ) of mammalian, plant and yeast proteins. Glc residues are immediately removed in the ER, where glycans play a key role in the solubility of the glycoproteins and in the so-called "quality control of glycoprotein folding" ${ }^{\prime 36}$. Cycles of glucosylation and deglucosylation occur in the endoplasmic 
reticulum (ER) until the glycoprotein is folded and continues the transit through the secretory pathway or, if unable to fold properly, is retrotranslocated to the cytosol and degraded by the proteasomes. This mechanism guarantees that only properly folded proteins are secreted. Once glycoproteins leave the ER, $\mathrm{N}$-glycans are remodeled in the transit through the golgi apparatus and acquire glycan structures that are species specific. In yeast $\mathrm{N}$-glycans in mature proteins are of high mannose type while in mammalian proteins are of complex or hybrid type ${ }^{37}$. O-glycosylation of $\mathrm{S}$ or $\mathrm{T}$ residues may also occur in the Golgi, but in this case the monosaccharides are added step by step, and are species specific. When RBD purified from $P$. pastoris and HEK-293T cells were treated with PNGaseF, which removes both high mannose and complex $N$-glycans, a similar band of $\sim 26 \mathrm{KDa}$ was observed by SDS-PAGE for both proteins, in agreement with the expected molecular weight of the proteins lacking $N$-glycans. However, only in the case of RBD obtained from $P$. pastoris the same band was observed when proteins were treated with EndoH, which removes high mannose glycans, indicating that RBD from $P$. pastoris bears only the expected high mannose $N$-glycans, while RBD from HEK-293T likely bears complex or hybrid ones. It has been previously reported that SARS-CoV-2 RBD is produced as two predominantly $N$-glycosylated forms of $\sim 34$ and $\sim 27$ kDa when expressed in Sf9 insect cells ${ }^{23}$.

Exhaustive removal of $\mathrm{N}$-glycans RBD obtained from HEK-293T cells produced two protein forms that migrated as distinct bands, suggesting the presence of either two $O$-glycosylated isoforms, or of two peptide isoforms. Shajahan and coworkers have evaluated the $O$-glycosylation of SARS-CoV-2 Spike protein produced in HEK-293 cells by searching LC-MS/MS data for common $O$-glycosylation modifications. These authors 
found $O$-glycosylation sites at positions T323 and S325, which provides further support to our suggestion ${ }^{37}$.

For secretory recombinant proteins produced in yeast, high mannose hyperglycosylation may be a major issue, as it may potentially alter functional properties of the proteins ${ }^{26}$. However, even though RBD expressed in HEK-293T and $P$. pastoris exhibited different glycosylation patterns, both conformational and stability studies carried out in the present work suggest that both polypeptides have similar structures. The stability of both forms was similarly sensitive to changes in ionic strength, a result in good agreement with our computational modelling, which predicts that a set of ionic interactions stabilizes RBD structure and most likely modulates its internal motions. Interestingly, when RBD was unfolded in the absence of reducing agents the process was reversible, as judged by the analysis of Trp fluorescence spectra, which suggests that Trp residue emission occurs in an apolar and likely more rigid environment upon refolding.

Previously, the thermal stability of a mutated version of RBD from SARS-CoV-1 Spike named RBD219-N1 (residues 319-536 from Spike, where the first Asn of RBD, residue 318 , was deleted to avoid glycosylation at the $\mathrm{N}$-terminal region of the protein) was analyzed by thermal shift monitoring of extrinsic fluorescence ${ }^{38}$. Remarkably, the RBD219-N1 denaturation profile showed an average melting temperature of approximately $57{ }^{\circ} \mathrm{C}$, a value significantly higher than that observed for RBD from SARS-CoV-2 in this work (approximately $50^{\circ} \mathrm{C}$ ), which might be due to the fact that denaturation of RBD219-N1 was carried out at a considerably lower ionic strength ${ }^{38}$. In addition, the $\mathrm{pH}$ of the protein sample was not constant throughout the experiment, given that the $\mathrm{pKa}$ of the Tris buffer used in this work is highly temperature dependent. 
Alternatively, the suppression of the N-terminal glycosylation in SARS-CoV-1 RBD might have an effect on its conformational stability. Nevertheless, the possibility that SARS-CoV-1 RBD has particular features that might increase its stability relative to that of SARS-CoV-2 RBD should not be excluded.

In our hands, RBD in its native state was stable under a broad range of $\mathrm{pH}$ and concentrations. Although it exhibited a low tendency to aggregate at high concentrations, no significant complications were observed during filter-protein concentration or dialysis, which was performed either to change the buffer or to remove imidazole after protein purification. Freezing $\left(-80^{\circ} \mathrm{C}\right)$ and subsequent thawing of RBD did not result in protein aggregation at protein concentrations of $30-40 \mu \mathrm{M}$ or lower, therefore this strategy was used for its storage, as it made unnecessary the use of stabilizing molecules such as glycerol or trehalose. However, it should be noted that RBD precipitation was occasionally observed after thawing, at protein concentrations above $80 \mu \mathrm{M}$.

P. pastoris-produced RBD was able to stimulate antibody production in mice, and the resulting immune sera were capable of detecting RBD produced not only in $P$. pastoris but also in HEK-293T cells. Finally, scaling up of RBD expression in P. pastoris could be performed in a bioreactor with yields greater than $45 \mathrm{mg} \mathrm{L}^{-1}$, which potentially allows the large scale immunization of animals in order to produce neutralizing antibodies, or the development of SARS-CoV-2 vaccines. Future biotechnological developments will be facilitated by the inclusion of a Sortase-A enzyme recognition site within the RBD coding sequence, which allows the native covalent coupling of RBD to fluorescent probes, peptides, proteins, or modified surfaces, through an efficient transpeptidation reaction ${ }^{39}$. Thus, the Sortase-A-mediated transpeptidation will allow 
future efficient in vitro covalent linking of RBD with protein carriers independently-produced in low cost systems such as $E$. coli.

\section{Methods}

\section{Expression of RBD in mammalian cells}

For RBD expression in mammalian cells, a DNA fragment optimized for expression in human cells encoding RBD (Spike residues from 319 to 537, preceded by the IL-2 export sequence (MYRMQLLSCIALSLALVTNS) and followed by a C-terminal Sortase-A recognition sequence for covalent coupling ${ }^{39}$ and a His6 tag for purification (LPETGHHHHHH) was synthesized by GenScript (NJ, USA) and cloned into the pCDNA3.1(+) plasmid vector (ampicillin R). Expression of RBD was carried out in the HEK-293T cell line kindly provided by Xavier Saelens (VIB-University of Ghent, Belgium). HEK-293T cells were grown in high glucose (4.5 $\mathrm{g} \mathrm{L}^{-1}$ glucose) Dulbecco's modified Eagle's medium (DMEM, Thermo Fisher Scientific) supplemented with $10 \%$ fetal bovine serum (FBS, Natocor), penicillin/streptomycin (100 units $\mathrm{mL}^{-1}$ and $100 \mu \mathrm{g} \mathrm{mL}$ respectively, Thermo Fisher Scientific) and $110 \mathrm{mg} \mathrm{L}^{-1}$ of sodium pyruvate (Thermo Fisher Scientific) in a $37^{\circ} \mathrm{C}$ humidified incubator containing $5 \% \mathrm{CO}_{2}$. Cells were plated $(2$ x $10^{7}$ cells per $150 \mathrm{~mm}$ plate) and grown for $24 \mathrm{~h}$ before transfection with Polyethylenimine (PEI, Sigma) according to the manufacturer's instructions. Cells were grown for $72 \mathrm{~h}$ before harvesting the culture medium.

Mammalian cell culture medium was centrifuged twice at $12,0000 x g$ for 20 min at $4{ }^{\circ} \mathrm{C}$, later the supernatant $\mathrm{pH}$ was adjusted to 8.0 with equilibration buffer $(50 \mathrm{mM}$ sodium phosphate, $300 \mathrm{mM} \mathrm{NaCl}$ and $20 \mathrm{mM}$ imidazole, $\mathrm{pH}$ 8,0). RBD was purified using a previously equilibrated $\mathrm{Ni}^{2+}$-NTA-agarose column. RBD was eluted by increasing 
concentrations of imidazole prepared in the equilibration buffer. Fractions containing the recombinant protein, as judged by the SDS-PAGE analysis, were pooled and dialyzed against a buffer without imidazole (20 mM Sodium phosphate, $150 \mathrm{mM} \mathrm{NaCl}$, $\mathrm{pH}=7,4)$.

\section{Expression of RBD in Pichia pastoris}

The RBD coding sequence with codon optimization for P. pastoris (Spike amino acid residues 319-537) fused to the Saccharomyces cerevisiae alpha factor secretion signal ( $\mathrm{N}$-terminal) ${ }^{40}$ followed by a C-terminal Sortase-A recognition sequence and a His6 tag (C-terminal) was synthesized and cloned into pPICZalpha by GenScript (NJ, USA) using EcoRI and Sacll restriction sites to produce pPICZalphaA-RBD-Hisx6.

The Sacl linearized pPICZalphaA-RBD-Hisx6 vector $(10 \mu \mathrm{g})$ was used to transform electrocompetent X-33 P. pastoris strain at $2.5 \mathrm{kV}, 25 \mathrm{uF}, 200 \mathrm{ohm}$. Cells recovered in ice-cold 1.0 M sorbitol (Sigma) were plated in YPDS (YPD: 1\% yeast extract, 2\% bactopeptone (Difco), 2\% glucose, plus $1.0 \mathrm{M}$ sorbitol) supplemented with $100 \mu \mathrm{gL}^{-1}$ zeocin (Invitrogen) and incubated four days at $28{ }^{\circ} \mathrm{C}$. Selected colonies (45) were transferred to increasing amounts of zeocin $\left(100\right.$ to $\left.500 \mu \mathrm{g} \mathrm{mL} \mathrm{L}^{-1}\right)$. The integration at AOX site in clones that were resistant to the highest amount of zeocin was confirmed by colony PCR using primers AOX $_{\text {for }}\left(5^{\prime}-\right.$ GACTGGTTCCAATTGACAAGC- $\left.3^{\prime}\right)$ and RBD $_{\text {rev }}\left(5^{\prime}\right.$ GTTCCATGCAATGACGCATC 3').

For RBD production in batch, single colonies were used to inoculate BMGY medium ( $1 \%$ yeast extract, $2 \%$ bactopeptone, $1.34 \% \mathrm{YNB}, 400 \mu \mathrm{gL}^{-1}$ biotin, $0.1 \mathrm{M}$ potassium phosphate, $\mathrm{pH} 6.0$, and $1 \%$ glycerol) and cultures were grown at $28^{\circ} \mathrm{C}$ with agitation at $250 \mathrm{rpm}$ until the culture reached a $\mathrm{OD}_{600 \mathrm{~nm}}=4-6$. Cells were harvested, resuspended in either Buffered Methanol-complex Medium (BMMY: 1\% yeast extract, 
(Difco) $2 \%$ peptone, $100 \mathrm{mM}$ potassium phosphate $\mathrm{pH} 6.0,1.34 \% \mathrm{YNB}, 0.4 \mathrm{mg} \mathrm{L}^{-1}$ biotin, $0.5 \%$ methanol, Sintorgan) or buffered minimal methanol medium containing histidine (Sigma) (BMMH: $100 \mathrm{mM}$ potassium phosphate $\mathrm{pH}$ 6.0, 1.34\% YNB, $0.4 \mathrm{mg} \mathrm{L}^{-1}$ biotin, $4 \mathrm{mg} \mathrm{L}^{-1}$ histidine, $0.5 \%$ methanol) to an initial $\mathrm{DO}_{600 \mathrm{~nm}}=1.0$, and incubated at 28 ${ }^{\circ} \mathrm{C}$ with shaking at $250 \mathrm{rpm}$ in flasks covered with microporous tape sheets for better oxygenation. Every 24 hs methanol was added to a final concentration of $0.5 \%$ and $\mathrm{pH}$ was adjusted to 6 if necessary. Induction was maintained during $72-90 \mathrm{~h}$ at $28^{\circ} \mathrm{C}$, then cells were removed by centrifugation at $3000 \times \mathrm{g}$ for $10 \mathrm{~min}$ and the supernatant was frozen at $-80 \mathrm{C}$ until it was used.

The purification of RBD from culture media was performed using a NTA-Ni ${ }^{2+}$ column previously equilibrated with $50 \mathrm{mM}$ Tris- $\mathrm{HCl}, 150 \mathrm{mM} \mathrm{NaCl}, 10 \%$ glycerol, $\mathrm{pH}$ 8.0 (equilibration solution). The media supernatants was adjusted to $\mathrm{pH} 8.0$ with $\mathrm{NaOH}$, centrifuged $20 \mathrm{~min}$ at $12,000 \mathrm{xg}$ and loaded to the column. The flow through was reloaded twice. The column was washed with an equilibration solution containing 20-30 mM imidazole. Finally, RBD was eluted with an equilibration solution containing $300 \mathrm{mM}$ imidazole. The purified protein was dialyzed twice in $20 \mathrm{mM}$ Tris- $\mathrm{HCl}, 150 \mathrm{mM}$ $\mathrm{NaCl}$ buffer, $\mathrm{pH} 7.4$, and quantified by absorbance at $280 \mathrm{~nm}$ (see below) and stored at $-80^{\circ} \mathrm{C}$.

\section{UV Absorption Spectroscopy}

The concentration of recombinant RBD was determined by UV spectrophotometry, using the following extinction coefficients derived from the protein sequence (considering all the disulfide bonds formed): for RBD produced in $P$. pastoris: $\boldsymbol{\varepsilon}_{280 \mathrm{~nm}}=33850 \mathrm{M}^{-1} \mathrm{~cm}^{-1}$ (Abs ${ }_{280 \mathrm{~nm}}=1.304$ for a $1 \mathrm{mg} \mathrm{mL}^{-1}$ protein solution); for 
RBD produced in HEK-293T cells (without considering IL2 export signal sequence: $\varepsilon_{280 \mathrm{~nm}}=33850 \mathrm{M}^{-1} \mathrm{~cm}^{-1}$ (Abs $280=1.300$ for a $1 \mathrm{mg} \mathrm{mL}^{-1}$ protein solution).

Absorption spectra (240-340 $\mathrm{nm}$ range, using a 0.1-nm sampling interval) were acquired at $20{ }^{\circ} \mathrm{C}$ with a JASCO V730 BIO spectrophotometer (Japan). Ten spectra for each sample were averaged, and blank spectra (averaged) subtracted. A smoothing routine was applied to the data by using a Savitzky-Golay filter and subsequently the 4th derivative spectra were calculated.

\section{SDS-PAGE and Western Blotting Analysis}

Purified RBD produced in P. pastoris or in HEK-293T cells was boiled in sample buffer (4\% SDS, 20\% glycerol, 120 mM Tris, pH 6.8, 0.002\% bromophenol blue, $200 \mathrm{mM}$ 2-mercaptoethanol) and separated in 12\% SDS-PAGE. Proteins were either stained with Coomassie brilliant blue G-250 or transferred to nitrocellulose membranes (GE Healthcare). The membranes were blocked with $5 \%$ milk in $0.05 \%$ Tween TBS at room temperature for $1 \mathrm{~h}$ and then incubated at $4{ }^{\circ} \mathrm{C}$ overnight with a specific polyclonal serum produced by immunization of mice with RBD produced in HEK-293T cells. HRP-conjugated anti-mouse were incubated for $1 \mathrm{~h}$ at room temperature and visualized by enhanced chemiluminescence (ECL, Thermo Scientific).

\section{Circular Dichroism and Tryptophan Fluorescence}

CD spectra measurements were carried out at $20{ }^{\circ} \mathrm{C}$ with a Jasco J-815 spectropolarimeter. Far-UV and near-UV CD spectra were collected using cells with path lengths of 0.1 and $1.0 \mathrm{~cm}$, respectively. Data was acquired at a scan speed of 20 $\mathrm{nm} \min ^{-1}$ (five scans were averaged, scans corresponding to buffer solution were 
averaged and subtracted from the spectra). Values of ellipticity were converted to molar ellipticity.

Steady-state tryptophan fluorescence measurements were performed in an Aminco-Bowman Series 2 spectrofluorometer equipped with a thermostated cell holder connected to a circulating water bath set at $20^{\circ} \mathrm{C} . \mathrm{A} 0.3-\mathrm{cm}$ path length cell was used. The excitation wavelength was set to $295 \mathrm{~nm}$ and emission data were collected in the range $310-450 \mathrm{~nm}$. The spectral slit-width was set to $3 \mathrm{~nm}$ for both monochromators. The protein concentration was 3.0-5.0 $\mu \mathrm{M}$, and the measurements were performed in a buffer containing $20 \mathrm{mM}$ sodium phosphate, $150 \mathrm{mM} \mathrm{NaCl}$, pH 7.40 .

\section{Temperature-Induced Denaturation Monitored by Sypro-Orange}

Temperature-induced denaturation of RBD forms was monitored by the change in the Sypro Orange dye (Thermo Fisher) fluorescence using protein at a $5.0 \mu \mathrm{M}$ concentration in $50 \mathrm{mM}$ sodium phosphate buffer, $\mathrm{pH}$ 7.0. Samples without protein were also included as controls. The dye was used at $2 \times$ (as suggested by Thermo Fisher Scientific). The temperature slope was $1{ }^{\circ} \mathrm{C} \mathrm{min}^{-1}$ (from 20 to $90{ }^{\circ} \mathrm{C}$ ). Excitation and emission ranges were $470-500$ and $540-700 \mathrm{~nm}$ respectively.

The fluorescence signal was quenched in the aqueous environment but became unquenched when the probe bound to the apolar residues upon unfolding. Experiments by triplicate were carried out in a Step One Real-Time-PCR instrument (Applied Biosystems, CA, U.S.A.).

Hydrodynamic Behavior by SEC-HPLC 
SEC-HPLC was performed using a Superose-6 column (GE Healthcare). The protein concentration was $20-30 \mu \mathrm{M}$, a volume of $50 \mu \mathrm{L}$ was typically injected, and the running buffer was $20 \mathrm{mM}$ Tris- $\mathrm{HCl}, 100 \mathrm{mM} \mathrm{NaCl}, 1 \mathrm{mM}$ EDTA, $\mathrm{pH}$ 7.0. The experiment was carried out at room temperature $\left(\sim 25^{\circ} \mathrm{C}\right)$ at a $0.5 \mathrm{~mL} \mathrm{~min}{ }^{-1}$ flow rate. A JASCO HPLC instrument was used. It was equipped with an automatic injector, a quaternary pump and a UV-VIS UV-2075 (elution was monitored at $280 \mathrm{~nm}$ ).

\section{Production of RBD in P. pastoris by bioreactor fermentation}

P. pastoris was grown on a solid YPD medium containing $20 \mathrm{~g} \mathrm{~L}^{-1}$ peptone, $10 \mathrm{~g} \mathrm{~L}^{-1}$ yeast extract, $20 \mathrm{~g} \mathrm{~L}^{-1}$ glucose and $20 \mathrm{~g} \mathrm{~L}^{-1}$ agar medium at $30 \pm 1{ }^{\circ} \mathrm{C}$. As previously described by Chen and coworkers ${ }^{38}$, liquid cultivation was carried out using low salt medium (LSM) containing $4.55 \mathrm{~g} \mathrm{~L} \mathrm{~L}^{-1}$ potassium sulfate, $3.73 \mathrm{~g} \mathrm{~L} \mathrm{~L}^{-1}$ magnesium sulfate heptahydrate, $1.03 \mathrm{~g} \mathrm{~L}^{-1}$ potassium hydroxide, $0.23 \mathrm{~g} \mathrm{~L}^{-1}$ calcium sulfate anhydrous, 10.9 $\mathrm{mL} \mathrm{L}^{-1}$ phosphoric acid $85 \%$ and $40 \mathrm{~g} \mathrm{~L}^{-1}$ glycerol, in order to prevent salt precipitation during downstream processing due to increased $\mathrm{pH}$. After sterilization, $3.5 \mathrm{~mL}$ per liter of filtered biotin solution $(0.02 \% \mathrm{w} / \mathrm{v})$ and $3.5 \mathrm{~mL}$ per liter of trace metal solution (PTM1) were added. PTM1 contained per liter: 6.0 g copper (II) sulfate pentahydrate, $0.08 \mathrm{~g}$ sodium iodide, $3.0 \mathrm{~g}$ manganese sulfate-monohydrate, $0.2 \mathrm{~g}$ sodium molybdate-dihydrate, $0.02 \mathrm{~g}$ boric acid, $0.5 \mathrm{~g}$ cobalt chloride, $20.0 \mathrm{~g}$ zinc chloride, 65.0 g ferrous sulfate-heptahydrate, $0.2 \mathrm{~g}$ biotin and $5 \mathrm{~mL}$ sulfuric acid $5.0 \mathrm{~mL}$.

Fermentations were conducted in a stirred-tank bioreactor using a four-stage process based on Celik et al. ${ }^{26,41}$, with slight modifications. The first stage consisted in a batch culture using LSM medium with $40 \mathrm{~g} \mathrm{~L}^{-1}$ glycerol as carbon source and supplemented with $3.5 \mathrm{~mL} \mathrm{~L}^{-1}$ PTM1 and $3.5 \mathrm{~mL} \mathrm{~L}^{-1}$ biotin solution $(0.02 \% \mathrm{w} / \mathrm{v})$. Under 
these conditions yeast cells grew and reached high biomass levels without expression of RBD, as it was under the control of AOX1 promoter, which is repressed when glycerol is provided as an unlimited substrate. In the second phase, a glycerol solution (600 $\mathrm{g} \mathrm{L}^{-1}$ solution supplemented with $12 \mathrm{~mL} \mathrm{~L}^{-1}$ PTM1) was fed into the culture at a growth-limiting rate to increase cell concentration. At the same time, a gradual derepression of AOX1 promoter takes place under this glycerol-limited condition. This phase was initiated after glycerol depletion was evidenced by an oxygen spike. Glycerol feeding was automatically regulated according to the percentage of dissolved oxygen (DO \%) in the culture, with a cut-off of $60 \%$ saturation. Subsequently, a short transition stage was conducted by feeding a glycerol:methanol (3:1) mixture, thus allowing the adaptation of cells for the growth in the presence of methanol. Finally, the induction stage was carried out by adding pure methanol (supplemented with $12 \mathrm{ml} \mathrm{L}^{-1} \mathrm{PTM} 1$ ) in a fed-batch mode with a growth-limiting rate. Methanol feeding was also automatically regulated according to the level of DO \% in the culture, with a cut-off $50 \%$ saturation.

In order to obtain the inoculum for bioreactor fermentations, transformed $P$. pastoris cells grown on YPD agar plates were inoculated into a $100-\mathrm{mL}$ flask containing $20 \mathrm{~mL}$ of LSM medium with $10 \mathrm{~g} \mathrm{~L}^{-1}$ glycerol (supplemented with PTM1 and biotin) and cultured overnight at $30 \pm 1^{\circ} \mathrm{C}$. A volume of $300 \mathrm{~mL}$ of $\mathrm{LSM}$ containing $10 \mathrm{~g} \mathrm{~L}^{-1}$ glycerol (supplemented with PTM1 and biotin) in a 1 L Erlenmeyer flask was inoculated with the overnight culture and incubated at $30 \pm 1^{\circ} \mathrm{C}$ until the culture reached an $\mathrm{OD}_{600}$ of $\sim 16$. This culture was used to inoculate $3 \mathrm{~L}$ of LSM with $40 \mathrm{~g} \mathrm{~L}^{-1}$ glycerol (supplemented with 3.5 $\mathrm{mL} \mathrm{L}^{-1}$ PTM1 and $3.5 \mathrm{ml} \mathrm{L}^{-1}$ biotin $0.02 \% \mathrm{w} / \mathrm{v}$ ) in a 7-L BioFlo 115 bioreactor (New Brunswick Scientific; Edison, NJ), which was interfaced with Biocommand Bioprocessing software (New Brunswick Scientific) for parameter control and data acquisition. 
Temperature was maintained at $30 \pm 1^{\circ} \mathrm{C}$ throughout batch and glycerol fed-batch phases and at $25 \pm 1^{\circ} \mathrm{C}$ during transition and induction stages. The $\mathrm{pH}$ was maintained at 5.0 during the first two phases, and at 5.5 in the last two, by adding $\mathrm{H}_{3} \mathrm{PO}_{4}$ (42.5\%) and $14 \%(\mathrm{v} / \mathrm{v}) \mathrm{NH}_{4} \mathrm{OH}$, which also served as a nitrogen source. DO \% was regulated by an agitation cascade (maximum of $1200 \mathrm{rpm}$ ) and supplemented with filter-sterilized $(0.22 \mu \mathrm{m})$ air and pure oxygen when needed. The $\mathrm{pH}$ was measured using a $\mathrm{pH}$ electrode (Mettler-Toledo $\mathrm{GmbH}$, Germany), and the oxygen concentration was measured with a polarographic probe (InPro6110/320, Mettler-Toledo GmbH). Foam formation was avoided by the addition of $3 \%(v / v)$ antifoam 289 (Sigma-Aldrich; St. Louis, MO). Samples were withdrawn throughout the fermentation process with the purpose of evaluating the biomass and recombinant protein expression.

The optical density of $P$. pastoris culture samples was measured at $600 \mathrm{~nm}$ using an UV-Vis spectrophotometer and converted to dry cell weights (DCW, in $\mathrm{g} \mathrm{L}^{-1}$ ) with a previously calculated DWC versus $\mathrm{OD}_{600 \mathrm{~nm}}$ calibration curve in accordance with the formula: $\mathrm{DCW}=0.269 \times \mathrm{OD}_{600 \mathrm{~nm}}, \mathrm{R}^{2}=0.99$.

The protein profile throughout the methanol-induction phase was analyzed by 12\% SDS-PAGE, and gels were stained with Coomassie brilliant blue G-250. RBD expression was confirmed by Western blot analysis using anti-RBD and anti-his antibodies. Total protein content was estimated by measuring the absorbance at 280 nm using a Beckman spectrophotometer.

\section{Glycan removal from RBD}

RBD $(5 \mu \mathrm{g})$ produced in HEK-293T cells or $P$. pastoris were denatured $10 \mathrm{~min}$ at $100{ }^{\circ} \mathrm{C}$ with $0.5 \%$ SDS and $40 \mathrm{mM}$ DTT. Then, $1 \%$ Nonidet P-40, $50 \mathrm{mM}$ buffer sodium phosphate buffer pH 7.5, and $50 \mathrm{mU}$ of PNGaseF (New England Biolabs) were added to 
remove complex glycans from RBD produced in HEK-293T cells. High mannose glycans of RBD produced in $P$. pastoris were removed by incubation with $5 \mathrm{mU}$ of EndoglycosidaseH (Roche) in $50 \mathrm{mM}$ sodium citrate buffer, $\mathrm{pH}$ 5.5. Reactions were incubated during $1 \mathrm{~h}$ at $37^{\circ} \mathrm{C}$ and analyzed by SDS-PAGE $12 \%$. Parallel control reactions were performed under the same conditions but without adding the endoglycosidase in each case.

\section{Bioinformatic Studies}

A total of 75355 amino acid sequences from Spike protein were downloaded from the Global Initiative for Sharing All Influenza Data (GISAID) database (https://www.gisaid.org) ${ }^{27}$. Multiple sequence alignment was obtained using MAFFT v. $7453^{42}$. The RBD region was extracted with the EMBOSS package ${ }^{43}$ using the RBD region of Uniprot accession QHN73795. Protein identity analysis was performed by BLAST using the RBD protein sequence as a query and an e-value of 0.001 was used. Sequence identity and coverage percentages were registered and counted.

\section{Reverse phase HPLC}

For HPLC, a JASCO system equipped with an autoinjector, an oven (thermostatized at $25^{\circ} \mathrm{C}$ ) and a UV detector was used. A gradient from 0 to $100 \%$ acetonitrile was performed $(0.05 \%$ TFA (v/v) was added to the solvents). An analytical C18 column was used (Higgins Analytical, Inc. U.S.A.), with a $1.0 \mathrm{~mL}$ min-1 flow.

\section{MALDI TOF for intact mass analysis}

The protein samples were analyzed using a MALDI TOF TOF mass spectrometer (Applied Biosystems 4800 Plus) operating in linear mode. Previously, the samples were desalted on ZipTip $\mathrm{C}_{4}$ column (Millipore, Merck KGaA, Darmstadt, Germany), then 
eluted in a matrix solution of sinapinic acid $10 \mathrm{mg} \mathrm{ml}^{-1}$ in $70 \%$ acetonitrile, $0.1 \%$ TFA or 2,5 dihydroxy benzoic acid $5 \mathrm{mg} \mathrm{ml}^{-1}$ in $70 \%$ acetonitrile, $0.1 \%$ TFA and deposited on the MALDI plate. The spots were allowed to dry and finally the samples were ablated using a pulsed Nd:YAG laser (355 nm). Spectra were acquired in positive or negative mode, depending on the sample characteristics.

\section{Tryptic digestion}

The protein samples were digested with trypsin (Promega, mass spectrometry grade) in $\left(\mathrm{NH}_{4}\right) \mathrm{HCO}_{3}$ buffer $(0.1 \mathrm{M}, \mathrm{pH} 8.0)$, after $\mathrm{ON}$ at $37^{\circ} \mathrm{C}$, the cysteine side chains were previously modified with DTT-iodoacetamide. The tryptic mixture was desalted using a $\mu$ ZipTip $\mu \mathrm{C}_{18}$ column (Millipore, Merck KGaA, Darmstadt, Germany) and were eluted with a saturated matrix solution of $\alpha$ cyano-4-hydroxycinnamic acid in acetonitrile:water (70:30, 0.1\% TFA). Alternatively, the samples were digested in a gel following a similar protocol to that used for in solution digestion, with a previous washing step.

\section{MALDI TOF TOF for tryptic peptides analysis}

The spectra were first acquired in reflectron mode and the main signals studied in MS/MS mode. The resulting MS/MS spectra were analyzed using the MASCOT search engine $^{44}$ (Matrix Science) program and $\mathrm{COMET}^{45}$ at Transproteomic Pipeline. Also, for the manual analysis of spectra in reflectron mode, the GPMAW (Lighthouse data) program was used.

\section{Molecular Modelling}

The molecular Modelling analysis of the RBD domain was done using the chain E of the $\mathrm{pdb}$ structure $6 \mathrm{MOJ}^{19}$. Figures of this structure were done using $\mathrm{VMD}^{46}$. The 
identification of residues making moderate and strong electrostatic interactions within RBD was performed using the Salt Bridges plug in of VMD. For the analysis we used a $6.0 \AA ̊$ cut-off distance between side chain oxygen and nitrogen atoms of residues $D, E, K$ and $\mathrm{R}$. The accessible surface area calculations for the residues of RBD was done using the GetArea server http://curie.utmb.edu/getarea.html using a $1.4 \AA \AA$ probe radius.

\section{Immunization protocols}

Immunization of mice was carried out by experts from the High Level Technological Service CONICET (STAN No. 4482), under ISO9001 guidelines and those from the Institutional Committee for the Care and Use of Laboratory Animals (CICUAL). BALB/C mice were obtained from the animal facility of the Faculty of Veterinary Sciences, University of La Plata (Argentina), and housed at the animal facility of the Instituto de Ciencia y Tecnología Dr. César Milstein, Fundación Pablo Cassará. Female mice (6-8 week-old) were immunized intraperitoneally with $40 \mu \mathrm{g}$ RBD protein produced in $P$. pastoris in the presence of the HPLC-grade phosphorothioate

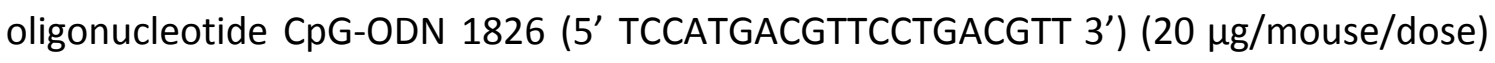
(Oligos etc. Inc., Integrated DNA Technologies, OR, USA) and aluminum hydroxide $\left(\mathrm{Al}(\mathrm{OH})_{3}\right) \quad(20 \%(\mathrm{v} / \mathrm{v}) /$ mouse/dose $)$ and boosted on day 30 with the same dose. Additional control animals were injected with $\mathrm{Al}(\mathrm{OH})_{3}(20 \%(\mathrm{v} / \mathrm{v}))$ plus CpG-ODN 1826 $(20 \mu \mathrm{g})$ per mouse with the same immunization schedule. Pre-immune sera also were collected before starting the immunization. Blood samples were obtained at 30 days post-first immunization (antigen prime) and 20 days post-second immunization (antigen boost) by venipuncture from the facial vein. After coagulation at room 
temperature for $1-2 \mathrm{~h}$, blood samples were spun in a centrifuge at $3000 \mathrm{rpm} / \mathrm{min}$ for 10 $\min$ at $4^{\circ} \mathrm{C}$. The upper serum layer was collected and stored at $-20^{\circ} \mathrm{C}$.

Identification of serum antibody against protein RBD in mice using an ELISA assay.

Standard ELISA procedures were followed to measure antibody response against RBD. Briefly, RBD protein produced in P. pastoris or HEK-293T cells was used to coat flat-bottom 96-well plates (Thermo Scientific NUNC-MaxiSorp) at a final concentration of $1 \mu \mathrm{g} / \mathrm{ml}(100 \mu \mathrm{l} /$ well) in phosphate-buffered saline (PBS) coating buffer ( $\mathrm{pH} 7.4)$ at $4{ }^{\circ} \mathrm{C}$ overnight. After blocking with $8 \%$ non-fat dry milk PBS for $2 \mathrm{~h}$ at $37^{\circ} \mathrm{C}$ the plates were washed 5 times with PBS containing 0.05\% Tween 20 (PBST). Serially diluted mouse sera were incubated at $37{ }^{\circ} \mathrm{C}$ for $1.5 \mathrm{~h}$ in PBS containing $1 \%$ non-fat dry milk (blocking solution), and then the plates were washed with PBST. For total specific IgG determination, IgG horseradish peroxidase (HRP)-conjugated antibody (DAKO P0447) was diluted 1/1000 in blocking solution and added to the wells. After incubation for $1 \mathrm{~h}$ at $37{ }^{\circ} \mathrm{C}$, plates were washed 5 times with PBST and developed with 3,3',5,5'-tetramethylbiphenyldiamine (TMB) for $15 \mathrm{~min}$. The reaction was stopped with $50 \mu \mathrm{l} /$ well of $1.0 \mathrm{M} \mathrm{H}_{2} \mathrm{SO}_{4}$ (stop solution). The absorbance was measured in a microplate reader (Thermo Multiscan FC ELISA) at $450 \mathrm{~nm}\left(\mathrm{~A}_{450}\right)$. The antibody titer was determined as the inverse of the last dilution that was considered positive, with a cut-off value defined as $A_{450}=0.20$, which was twice as high as that from a pool of Normal mice Sera (from 30 unimmunized animals). Statistical significance was evaluated by the Student's t-test, using a logarithmic transformation of the ELISA titers. Differences were considered significant if $p<0.05$.

\section{Acknowledgments}


We thank LANAIS-PRO-EM for the support with mass spectrometry analysis of proteins and peptides, and Fundación Ciencias Exactas y Naturales from Universidad de Buenos Aires for their help. We thank Dr. Juan Ugalde from UNSAM for providing a serum from mice immunized with RBD produced in HEK-293T. We would like to specially thank Dr. Diego U. Ferreiro for his initial suggestions concerning SARS-CoV-2 protein expression.

Author contributions (names must be given as initials)

All authors contributed equally to this work.

Additional Information (including a Competing Interests Statement)

The author(s) declare no competing interests.

\section{Funding Sources}

This study was supported by the Agencia Nacional de Promoción de la Investigación, el Desarrollo Tecnológico y la Innovación (ANPCyT) (IP-COVID-19-234), Consejo Nacional de Investigaciones Científicas y Técnicas (CONICET), Universidad de Buenos Aires (UBA) and Universidad Nacional de San Martín (UNSAM). We would like to thank the following Institutions for supporting MFP, NBF, NG and MI (CONICET), LAC and TI (ANPCYT), and MFP (F.A.R.A.).

\section{UniProt Accession IDs}

UniProtKB - PODTC2 (SPIKE_SARS2); Spike glycoprotein from SARS-CoV-2 .

\section{References}


1. Wang, C., Horby, P. W., Hayden, F. G. \& Gao, G. F. A novel coronavirus outbreak of global health concern. The Lancet 395, 470-473 (2020).

2. Schoeman, D. \& Fielding, B. C. Coronavirus envelope protein: current knowledge. Virology journal 16, 1-22 (2019).

3. Rota, P. A. et al. Characterization of a novel coronavirus associated with severe acute respiratory syndrome. science 300, 1394-1399 (2003).

4. Thiel, V. et al. Mechanisms and enzymes involved in SARS coronavirus genome expression. Journal of General Virology 84, 2305-2315 (2003).

5. Hulswit, R., De Haan, C. \& Bosch, B.-J. Coronavirus spike protein and tropism changes. in Advances in virus research vol. 96 29-57 (Elsevier, 2016).

6. Hui, D. S. Epidemic and emerging coronaviruses (severe acute respiratory syndrome and Middle East respiratory syndrome). Clinics in Chest Medicine 38, 71-86 (2017).

7. Kim, D. et al. The architecture of SARS-CoV-2 transcriptome. Cell (2020).

8. Lu, R. et al. Genomic characterisation and epidemiology of 2019 novel coronavirus: implications for virus origins and receptor binding. The Lancet 395, 565-574 (2020).

9. Zhou, P. et al. A pneumonia outbreak associated with a new coronavirus of probable bat origin. nature 579, 270-273 (2020).

10. Bolles, M., Donaldson, E. \& Baric, R. SARS-CoV and emergent coronaviruses: viral determinants of interspecies transmission. Current opinion in virology 1, 624-634 (2011).

11. Lam, T. T.-Y. et al. Identifying SARS-CoV-2-related coronaviruses in Malayan pangolins. Nature 1-4 (2020).

12. Xiao, K. et al. Isolation of SARS-CoV-2-related coronavirus from Malayan pangolins. 
Nature 1-4 (2020).

13. Ahmed, S. F., Quadeer, A. A. \& McKay, M. R. Preliminary identification of potential vaccine targets for the COVID-19 coronavirus (SARS-CoV-2) based on SARS-CoV immunological studies. Viruses 12, 254 (2020).

14. Zhang, T., Wu, Q. \& Zhang, Z. Probable pangolin origin of SARS-CoV-2 associated with the COVID-19 outbreak. Current Biology (2020).

15. Sanyal, D., Chowdhury, S., Uversky, V. N. \& Chattopadhyay, K. An exploration of the SARS-CoV-2 spike receptor binding domain (RBD), a complex palette of evolutionary and structural features. bioRxiv (2020).

16. Walls, A. C. et al. Structure, function, and antigenicity of the SARS-CoV-2 spike glycoprotein. Cell (2020).

17. Masters, P. S. The molecular biology of coronaviruses. Advances in virus research 66, 193-292 (2006).

18. Shang, J. et al. Structural basis of receptor recognition by SARS-CoV-2. Nature 581, 221-224 (2020).

19. Lan, J. et al. Structure of the SARS-CoV-2 spike receptor-binding domain bound to the ACE2 receptor. Nature 581, 215-220 (2020).

20. Watanabe, Y., Allen, J. D., Wrapp, D., McLellan, J. S. \& Crispin, M. Site-specific glycan analysis of the SARS-CoV-2 spike. Science (2020).

21. Grant, O. C., Montgomery, D., Ito, K. \& Woods, R. J. Analysis of the SARS-CoV-2 spike protein glycan shield: implications for immune recognition. bioRxiv (2020).

22. Casalino, L. et al. Shielding and Beyond: The Roles of Glycans in SARS-CoV-2 Spike Protein. bioRxiv (2020).

23. Yang, J. et al. A vaccine targeting the RBD of the $S$ protein of SARS-CoV-2 induces 
protective immunity. Nature 1-9 (2020).

24. Tai, W. et al. Characterization of the receptor-binding domain (RBD) of 2019 novel coronavirus: implication for development of RBD protein as a viral attachment inhibitor and vaccine. Cellular \& molecular immunology 17, 613-620 (2020).

25. Chen, W.-H. et al. Yeast-expressed recombinant protein of the receptor-binding domain in SARS-CoV spike protein with deglycosylated forms as a SARS vaccine candidate. Human vaccines \& immunotherapeutics 10, 648-658 (2014).

26. Çelik, E. \& Çalık, P. Production of recombinant proteins by yeast cells. Biotechnology advances 30, 1108-1118 (2012).

27. Elbe, S. \& Buckland-Merrett, G. Data, disease and diplomacy: GISAID's innovative contribution to global health. Global Challenges 1, 33-46 (2017).

28. Chan, J. F.-W. et al. A familial cluster of pneumonia associated with the 2019 novel coronavirus indicating person-to-person transmission: a study of a family cluster. The Lancet 395, 514-523 (2020).

29. Qeli, E. et al. Improved prediction of peptide detectability for targeted proteomics using a rank-based algorithm and organism-specific data. Journal of proteomics 108, 269-283 (2014).

30. Desiere, F. et al. The peptideatlas project. Nucleic acids research 34, D655-D658 (2006).

31. Deutsch, E. W. et al. A guided tour of the Trans-Proteomic Pipeline. Proteomics 10, 1150-1159 (2010).

32. Deutsch, E. W. et al. Trans-Proteomic Pipeline, a standardized data processing pipeline for large-scale reproducible proteomics informatics. PROTEOMICS-Clinical Applications 9, 745-754 (2015). 
33. Goldberg, D. S., Bishop, S. M., Shah, A. U. \& Sathish, H. A. Formulation development of therapeutic monoclonal antibodies using high-throughput fluorescence and static light scattering techniques: role of conformational and colloidal stability. Journal of pharmaceutical sciences 100, 1306-1315 (2011).

34. Chen, J. et al. Receptor-binding domain of SARS-CoV spike protein: soluble expression in E. coli, purification and functional characterization. World Journal of Gastroenterology: WJG 11, 6159 (2005).

35. Chuck, C.-P. et al. Expression of SARS-coronavirus spike glycoprotein in Pichia pastoris. Virus genes 38, 1-9 (2009).

36. D'Alessio, C., Caramelo, J. J. \& Parodi, A. J. UDP-GIC: glycoprotein glucosyltransferase-glucosidase II, the ying-yang of the ER quality control. in vol. 21 491-499 (Elsevier, 2010).

37. Shajahan, A., Supekar, N. T., Gleinich, A. S. \& Azadi, P. Deducing the N-and O-glycosylation profile of the spike protein of novel coronavirus SARS-CoV-2. bioRxiv (2020).

38. Chen, W.-H. et al. Optimization of the production process and characterization of the yeast-expressed SARS-CoV recombinant receptor-binding domain (RBD219-N1), a SARS vaccine candidate. Journal of pharmaceutical sciences 106, 1961-1970 (2017).

39. Pishesha, N., Ingram, J. R. \& Ploegh, H. L. Sortase A: a model for transpeptidation and its biological applications. Annual review of cell and developmental biology 34, 163-188 (2018).

40. Brake, A. J. et al. Alpha-factor-directed synthesis and secretion of mature foreign proteins in Saccharomyces cerevisiae. Proceedings of the National Academy of 
Sciences 81, 4642-4646 (1984).

41. Celik, E., Çalık, P. \& Oliver, S. G. Fed-batch methanol feeding strategy for recombinant protein production by Pichia pastoris in the presence of co-substrate sorbitol. Yeast 26, 473-484 (2009).

42. Katoh, K. \& Standley, D. M. MAFFT multiple sequence alignment software version 7: improvements in performance and usability. Molecular biology and evolution 30, 772-780 (2013).

43. Rice, P., Longden, I. \& Bleasby, A. EMBOSS: the European molecular biology open software suite. (2000).

44. Perkins, D. N., Pappin, D. J., Creasy, D. M. \& Cottrell, J. S. Probability-based protein identification by searching sequence databases using mass spectrometry data. ELECTROPHORESIS: An International Journal 20, 3551-3567 (1999).

45. Eng, J. K., Jahan, T. A. \& Hoopmann, M. R. Comet: an open-source MS/MS sequence database search tool. Proteomics 13, 22-24 (2013).

46. Humphrey, W., Dalke, A. \& Schulten, K. VMD: visual molecular dynamics. Journal of molecular graphics 14, 33-38 (1996).

\section{Argentinian AntiCovid Consortium:}

Claudia R. Arbeitman, ${ }^{1,2,3}$ Gabriela Auge, ${ }^{1,4}$ Matías Blaustein, ${ }^{1,4}$ Luis Bredeston, ${ }^{5,6}$ Enrique S. Corapi, ${ }^{4}$ Patricio O. Craig, ${ }^{7,8}$ Leandro A. Cossio, ${ }^{9,22}$ Liliana Dain, ${ }^{1,4,10}$ Cecilia D'Alessio, ${ }^{1,4}$ Fernanda Elias, ${ }^{11}$ Natalia B. Fernández, ${ }^{1,4}$ Javier Gasulla, ${ }^{1,4,12}$ Natalia Gorojovsky, ${ }^{7,8}$ Gustavo E. Gudesblat, ${ }^{1,4}$ María G. Herrera, ${ }^{1,4}$ Lorena I. Ibañez, ${ }^{13,14}$ Tommy Idrovo, ${ }^{4}$ Matías Iglesias Randon, ${ }^{5,8}$ Laura Kamenetzky, ${ }^{4,15}$ Alejandro D. Nadra, ${ }^{1,4}$ Diego G. Noseda ${ }^{16}$, Carlos H. Paván, ${ }^{17,18}$ María F. Pavan, ${ }^{13,14}$ María F. Pignataro, ${ }^{4}$ Ernesto Roman, ${ }^{6,7}$ Lucas A. M. Ruberto, ${ }^{19,20,21}$ Natalia Rubinstein, ${ }^{1,4}$ Javier Santos, ${ }^{1,4,7}$ Francisco Velazquez Duarte $^{4,8}$ and Alicia M. Zelada ${ }^{9,22}$.

${ }^{1}$ Consejo Nacional de Investigaciones Científicas y Técnicas (CONICET). Godoy Cruz 2290 C1425FQB, Buenos Aires, Argentina. 
${ }^{2}$ GIBIO-Universidad Tecnológica Nacional-Facultad Regional Buenos Aires. Medrano 951 C1179AAQ, Buenos Aires, Argentina.

${ }^{3}$ Theoretical Physics and Center of Interdisciplinary Nanostructure Science and Technology, Universität Kassel. Heinrich-Plett-Str. 40, 34132, Kassel, Germany.

${ }^{4}$ Universidad de Buenos Aires. Facultad de Ciencias Exactas y Naturales. Departamento de Fisiología y Biología Molecular y Celular. Instituto de Biociencias, Biotecnología y Biología Traslacional (iB3). Buenos Aires, Argentina.

${ }^{5}$ Universidad de Buenos Aires. Facultad de Farmacia y Bioquímica. Departamento de Química Biológica. Junín 965 C1113AAD. Buenos Aires, Argentina.

${ }^{6}$ CONICET-Universidad de Buenos Aires. Instituto de Química y Fisicoquímica Biológicas. (IQUIFIB). Buenos Aires, Argentina.

${ }^{7}$ Universidad de Buenos Aires. Facultad de Ciencias Exactas y Naturales. Departamento de Química Biológica. Buenos Aires, Argentina.

${ }^{8}$ CONICET-Universidad de Buenos Aires. Instituto de Química Biológica de la Facultad de Ciencias Exactas y Naturales (IQUIBICEN). Buenos Aires, Argentina.

${ }^{9}$ Universidad de Buenos Aires. Facultad de Ciencias Exactas y Naturales. Departamento de Fisiología y Biología Molecular y Celular. Laboratorio de Agrobiotecnología. Buenos Aires, Argentina.

${ }^{10}$ Centro Nacional de Genética Médica, Avda Las Heras 2670, 3er piso, C1425ASP, Buenos Aires, Argentina.

${ }^{11}$ Instituto de Ciencia y Tecnología Dr. César Milstein (Consejo Nacional de Investigaciones Científicas y Técnicas-Fundación Pablo Cassará). Saladillo 2468 C1440FFX, Buenos Aires, Argentina.

${ }^{12}$ Universidad Nacional de la Plata-CONICET. Centro de Investigaciones del Medio Ambiente (CIM). La Plata, Argentina.

${ }^{13}$ Consejo Nacional de Investigaciones Científicas y Técnicas (CONICET). Instituto de Ciencia y Tecnología Dr. César Milstein. Saladillo 2468, C1440FFX, Buenos Aires, Argentina.

${ }^{14}$ CONICET-Universidad de Buenos Aires. Instituto de Química Física de los Materiales, Medio Ambiente y Energía (INQUIMAE), Buenos Aires, Argentina.

${ }^{15}$ CONICET-Universidad de Buenos Aires. Facultad de Medicina. Instituto de Investigaciones en Microbiología y Parasitología (IMPaM). Buenos Aires, Argentina.

${ }^{16}$ Universidad Nacional de San Martín-CONICET. Instituto de Investigaciones Biotecnológicas (IIBio). San Martín, Buenos Aires, Argentina. 
${ }^{17}$ Universidad de Buenos Aires. Facultad de Farmacia y Bioquímica. Buenos Aires, Argentina.

${ }^{18}$ CONICET-Universidad de Buenos Aires. Facultad de Medicina. LANAIS-PROEM. Instituto de Química y Fisicoquímica Biológicas. (IQUIFIB). Buenos Aires, Argentina.

${ }^{19}$ Universidad de Buenos Aires. Facultad de Farmacia y Bioquímica. Departamento de Microbiología, Inmunología, Biotecnología y Genética. Buenos Aires, Argentina.

${ }^{20}$ CONICET-Universidad de Buenos Aires. Facultad de Farmacia y Bioquímica. Instituto de Nanobiotecnología (NANOBIOTEC). Buenos Aires. Argentina.

${ }^{21}$ Instituto Antártico Argentino. Ministerio de Relaciones Exteriores y Culto. Buenos Aires, Argentina.

${ }^{22}$ CONICET-Universidad de Buenos Aires. Instituto de Biodiversidad y Biología Experimental y Aplicada (IBBEA). Buenos Aires, Argentina.

*All authors (listed in alphabetical order) contributed equally to this work.

Contact E-mail: anticovid.arg@gmail.com 